\title{
Coupling Influence between Recycled Ceramics and Grazed Hollow Beads on Mechanical Properties and Thermal Conductivity of Recycled Thermal Insulation Concrete
}

\author{
Ying $\mathrm{Yu}^{*}+{ }^{\dagger}, \mathrm{Ben} \mathrm{Li}^{*}+\dagger$ and Dongmei Luo \\ Advanced and Sustainable Infrastructure Materials Group, School of Transportation, \\ Civil Engineering and Architecture, Foshan University, Foshan 528000, China; dmluo@fosu.edu.cn \\ * Correspondence: fhwu0509@fosu.edu.cn (Y.Y.); Liben89@fosu.edu.cn (B.L.) \\ + Ying Yu and Ben Li contributed equally to this work as co-first author.
}

check for updates

Citation: Yu, Y.; Li, B.; Luo, D. Coupling Influence between Recycled Ceramics and Grazed Hollow Beads on Mechanical Properties and Thermal Conductivity of Recycled Thermal Insulation Concrete. Materials 2021, 14, 4695. https:// doi.org/10.3390/ma14164695

Academic Editor: Dolores Eliche Quesada

Received: 3 July 2021

Accepted: 18 August 2021

Published: 20 August 2021

Publisher's Note: MDPI stays neutral with regard to jurisdictional claims in published maps and institutional affiliations.

Copyright: (c) 2021 by the authors. Licensee MDPI, Basel, Switzerland. This article is an open access article distributed under the terms and conditions of the Creative Commons Attribution (CC BY) license (https:/ / creativecommons.org/licenses/by/ $4.0 /)$.

\begin{abstract}
This paper investigated the influence of recycled ceramics and grazed hollow beads on the mechanical, thermal conductivity and material properties of concrete. The results showed that the concentration of recycled ceramics and grazed hollow beads has significant optimization on the workability and thermal properties of the concrete. However, the superabundant concentration can reduce the hydration degree of the concrete, which results in the suppressed production of C-S-H gel and the increase of material defects. In summary, considering the coordinated development of key factors such as thermal insulation properties, mechanical properties and microstructure, 10\% RCE and $60 \% \mathrm{GHB}$ are the optimal material system design methods.
\end{abstract}

Keywords: recycled ceramics (RCE); grazed hollow beads (GHB); recycled thermal insulation concrete (RTIC); mechanical properties; thermal conductivity; materials properties

\section{Introduction}

Environmental pollution and resource and energy shortages have become the main problems hindering the development of industrialization and urban construction [1-5]. With the continual improvement of industrialization processes, the accumulated storage volume of industrial waste has rapidly increased, causing irreversible environmental damage, such as soil erosion, air pollution, landscape destruction, deterioration of wildlife habitat and serious personal and property losses [6-8]. As the largest consumption carrier of industrial waste, concrete is gradually being recognized by government departments and the public for its role in the sustainable development of green ecology. Simultaneously, with the supersaturated population growth rate and the development of urbanization, the demand for concrete still maintains a relatively high volume. Recycling waste materials into concrete may be a necessary means for solving the above problems. On the one hand, it absorbs recyclable industrial waste to prepare new green building materials. On the other hand, it saves the non-renewable raw materials consumed in the traditional concrete preparation process [9-16]. As the world's largest ceramic producer and consumer, Foshan had produced more than 9 million tons of ceramics with a scrap rate of 5-25\% by 2020 [17-20]. However, China's disposal of waste ceramics is still in the stage of centralized burial, which has largely caused a waste of resources and environmental pollution. The resource utilization methods and methods of waste ceramic disposal have become the hotspots and key points in the current research in the field. In recent years, many scholars have carried out research on recycled ceramic aggregate concrete. The research results can be summarized as: (1) Due to the effect of the characteristics of ceramic aggregates, the replacement of natural coarse aggregates with ceramic coarse aggregates will lead to a decrease in the relative volume and fluidity of the mortar in the concrete. (2) Simultaneously, the compressive strength decreases as the replacement rate of ceramic coarse aggregate 
increases. (3) The flexural strength of recycled ceramic coarse aggregate concrete decreases with the increase of the ceramic coarse aggregate replacement rate because the crushing index of ceramic coarse aggregate is higher than that of natural coarse aggregate [21-25].

Based on the characteristics that the mechanical properties of recycled ceramic coarse aggregate concrete are lower than ordinary concrete, recycled ceramic concrete is more widely used in the preparation of enclosure structures. The engineering application of the envelope structure with heat preservation and heat insulation properties can effectively alleviate the problem of energy shortage in China which conforms to the fundamental national policy of energy saving and emission reduction [26-30]. Based on ceramic coarse aggregates, lightweight thermal insulation concrete structures can be prepared. However, due to the complex material properties of ceramic coarse aggregates, thermal insulation concrete has the disadvantages of uneven temperature distribution and high thermal conductivity. At present, the preparation of thermal insulation concrete structures with ceramic coarse aggregates is still unable to fully meet engineering needs. How to improve the thermal insulation performance of recycled ceramic coarse aggregate concrete and meet the needs of engineering applications is still an urgent problem to be solved. In recent years, as a new type of lightweight aggregate, grazed hollow beads (GHB) have the characteristics of a porous inner surface and a glass-like outer surface, and have the function of a micro pump, which is easy to combine with cementitious materials. At the same time, the concrete prepared with GHB as lightweight aggregate has good mechanical and thermal insulation properties [16,31-38]. However, the research on the mechanical properties, thermal conductivity and material properties of cement-based material systems prepared by combining GHB and ceramic coarse aggregates is insufficient, and it is still necessary to enrich the mechanism research of the basic material system to support its engineering applications.

The goal of this study is to fill these research gaps by investigating the mechanical properties, thermal conductivity and material characteristics of recycled thermal insulation concrete (RTIC) that incorporates grazed hollow beads and recycled ceramics as replacement fine and coarse aggregates. Slump, density, splitting strength, compressive strength, axial compressive strength, elastic modulus and thermal conductivity were measured to evaluate the impact of grazed hollow beads and recycled ceramics on the macroperformance. Material morphology, hydration products and functional groups were investigated to determine the mesoscopic properties of recycled thermal insulation concrete. In summary, based on the above research results, new ideas are provided for the actual use of lightweight thermal insulation cement-based materials in civil engineering, such as the construction of thermal insulation structural floor slabs and the preparation of special concrete structures.

\section{Materials and Methods}

\subsection{Raw Materials and Mixing Proportions}

Ordinary Portland Cement (P.O. 42.5 N), local nature sand (NSD), grazed hollow beads (GHB), recycled ceramics (RCE) and nature stone (NSE) were used throughout the experiment. The mechanical properties of cement and chemical composition of cement are shown in Tables 1 and 2. The particle size distribution curves of nature sand and nature stone are shown in Figures 1 and 2. The physical properties of local nature sand, grazed hollow beads, recycled ceramics and nature stone are shown in Table 3. In this paper, the grazed hollow beads were used for replacing nature sand in different volume ratios as 0,20 , $40,60 \%$ and the recycled ceramics were used for replacing nature stone in different mass ratios as $0,10,20,30 \%$. The replacement methods for grazed hollow beads and recycled ceramics are shown in Figure 3. The water-to-cement ratio $(w / c)$ was 0.5 and the mixing proportions of the concrete mixtures are listed in Table 4. In the process of preparing concrete, the use of traditional mixing preparation methods caused the concrete slump to fail to meet the specification requirements due to the high water absorption of RCE and GHB. In order to solve this problem, the RCE was pre-wetted during the preparation 
process, and then the GHB was pretreated by the free water-cement ratio method, and the moisture required to be absorbed by the GHB was calculated. Finally, the actual water demand during concrete preparation was calculated for final mixing preparation.

Table 1. Mechanical properties of Portland cement (MPa).

\begin{tabular}{ccccccc}
\hline \multicolumn{2}{c}{ Flexural Strength $\mathbf{( M P a})$} & \multicolumn{2}{c}{ Compressive Strength $\mathbf{( M P a )}$} & Fineness & \multicolumn{2}{c}{ Setting Time (min) } \\
\hline 3 days & 28 days & 3 days & 28 days & \multirow{2}{*}{1.2} & Initial setting & Final setting \\
$4.2 \pm 0.2$ & $7.5 \pm 0.5$ & $23.5 \pm 0.8$ & $43.2 \pm 0.4$ & & 186 & 252 \\
\hline
\end{tabular}

Table 2. Chemical properties of Portland cement (\%).

\begin{tabular}{cccccccc}
\hline Compounds & $\mathrm{SiO}_{2}$ & $\mathrm{Al}_{2} \mathrm{O}_{3}$ & $\mathrm{Fe}_{2} \mathrm{O}_{3}$ & $\mathrm{CaO}$ & $\mathrm{MgO}$ & $\mathrm{SO}_{3}$ & Loss \\
\hline Content & 22.53 & 4.42 & 2.06 & 61.71 & 4.55 & 2.23 & 2.86 \\
\hline
\end{tabular}

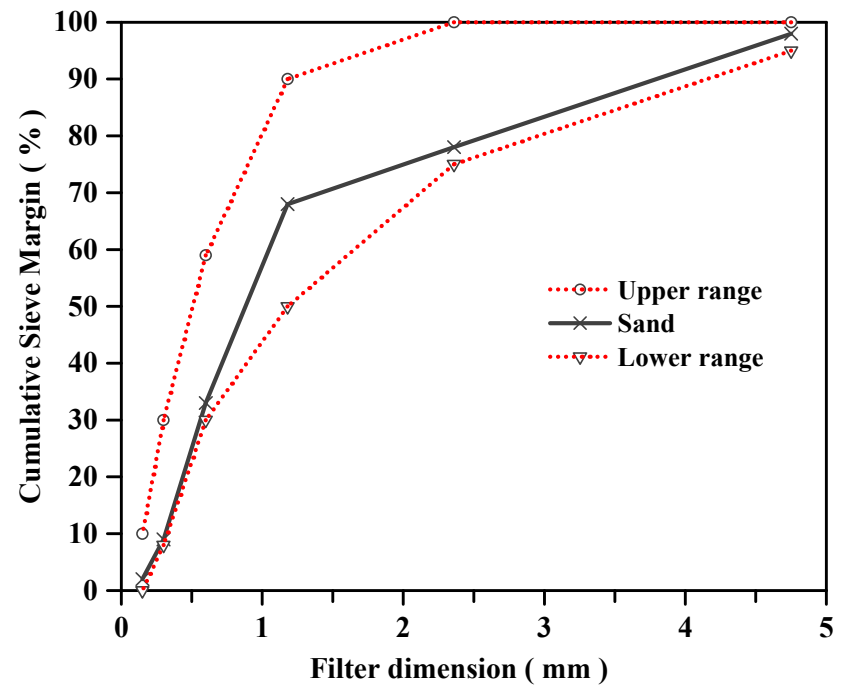

Figure 1. The particle size distribution curves of nature sand.

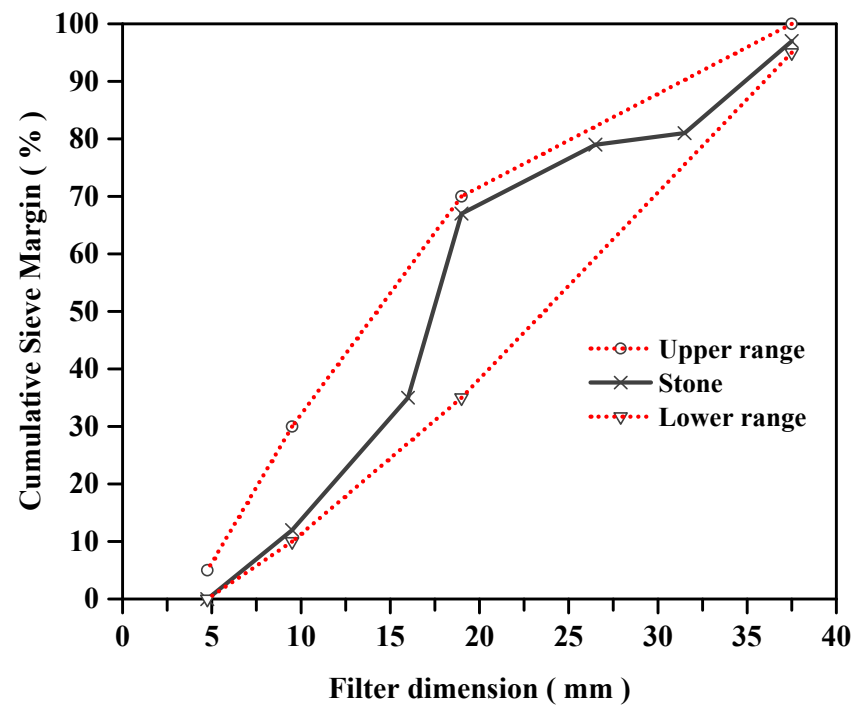

Figure 2. The particle size distribution curves of nature stone. 
Table 3. Properties of nature sand, grazed hollow beads, nature stone and recycled ceramic.

\begin{tabular}{ccccc}
\hline Physical Properties & \multicolumn{2}{c}{ Fine Aggregate } & \multicolumn{2}{c}{ Coarse Aggregate } \\
Type & NSD & GHB & NSE & RCE \\
Accumulation density $\left(\mathrm{kg} / \mathrm{m}^{3}\right)$ & 2050 & 99.52 & 1389 & 972 \\
Apparent density $\left(\mathrm{kg} / \mathrm{m}^{3}\right)$ & 2512 & 174.7 & 3045 & 1819 \\
Water content $(\%)$ & 0.81 & 0.5 & 0.12 & 2.51 \\
Mass water absorption $(\%)$ & 7.58 & 246 & 0.16 & 15.47 \\
Crushing value $(\%)$ & - & 0.072 & - & - \\
Thermal conductivity $(\mathrm{W} / \mathrm{m} \cdot \mathrm{K})$ & - & - & -95 \\
\hline
\end{tabular}

Note: The crushing value is the ultimate compressive strength of the coarse aggregate used in the concrete preparation process. It is one of the required attributes in raw material performance research.

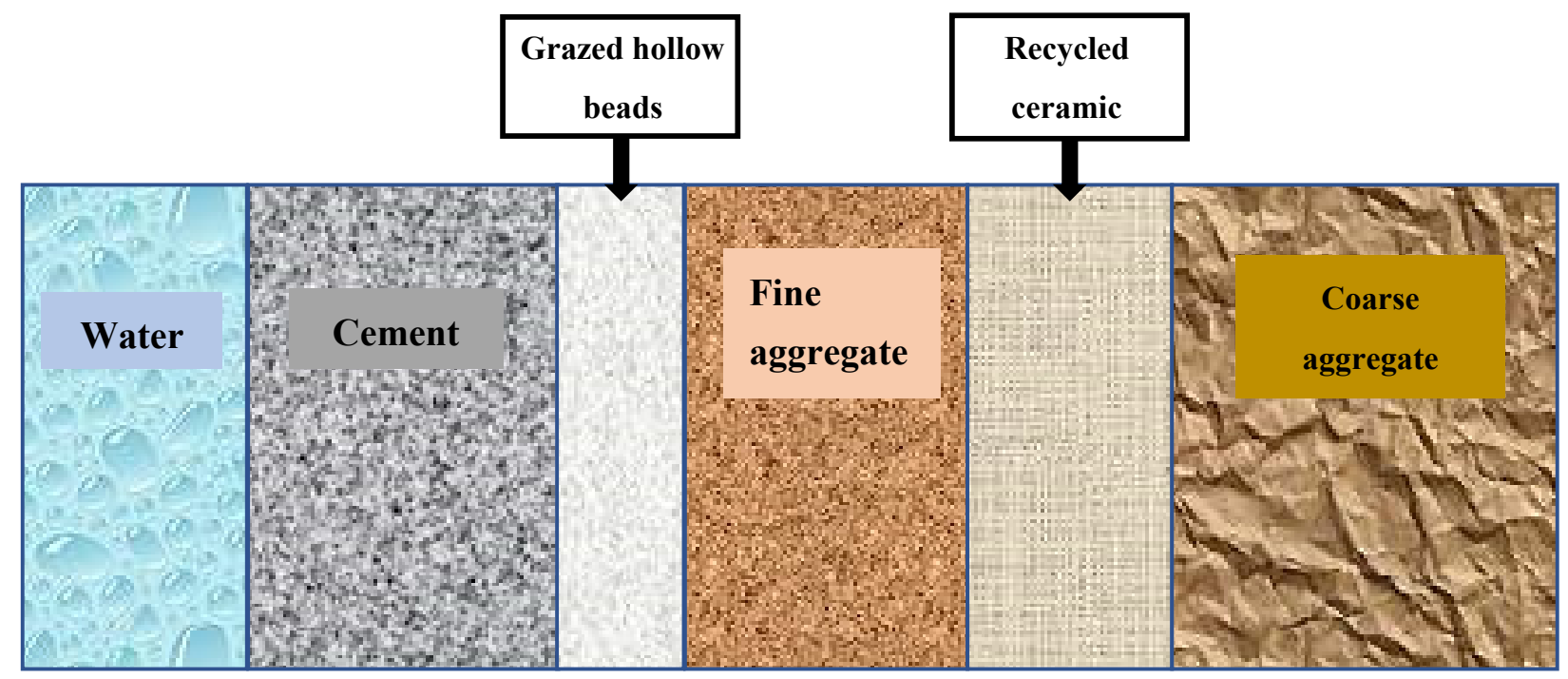

Figure 3. The replacement methods for RCE and GHB.

Table 4. Mixing proportions of concrete mixtures $\left(\mathrm{kg} / \mathrm{m}^{3}\right)$.

\begin{tabular}{|c|c|c|c|c|c|c|c|}
\hline $\mathrm{W} / \mathrm{C}=0.5$ & Cement & Water & NSD & NSE & RCE & GHB & SP \\
\hline RCE0 GHB0 & 370 & 185 & 628 & 1218 & 0 & 0 & 1.9 \\
\hline RCE0 GHB20 & 370 & 202.8 & 628 & 1218 & 0 & 19.9 & 1.9 \\
\hline RCE0 GHB40 & 370 & 220.5 & 628 & 1218 & 0 & 39.8 & 1.9 \\
\hline RCE0 GHB60 & 370 & 238.3 & 628 & 1218 & 0 & 59.7 & 1.9 \\
\hline RCE10 GHB0 & 370 & 185 & 628 & 1096 & 122 & 0 & 1.9 \\
\hline RCE10 GHB20 & 370 & 202.8 & 628 & 1096 & 122 & 19.9 & 1.9 \\
\hline RCE10 GHB40 & 370 & 220.5 & 628 & 1096 & 122 & 39.8 & 1.9 \\
\hline RCE10 GHB60 & 370 & 238.3 & 628 & 1096 & 122 & 59.7 & 1.9 \\
\hline RCE20 GHB0 & 370 & 185 & 628 & 974 & 244 & 0 & 1.9 \\
\hline RCE20 GHB20 & 370 & 202.8 & 628 & 974 & 244 & 19.9 & 1.9 \\
\hline RCE20 GHB40 & 370 & 220.5 & 628 & 974 & 244 & 39.8 & 1.9 \\
\hline RCE20 GHB60 & 370 & 238.3 & 628 & 974 & 244 & 59.7 & 1.9 \\
\hline RCE30 GHB0 & 370 & 185 & 628 & 853 & 365 & 0 & 1.9 \\
\hline RCE30 GHB20 & 370 & 202.8 & 628 & 853 & 365 & 19.9 & 1.9 \\
\hline RCE30 GHB40 & 370 & 220.5 & 628 & 853 & 365 & 39.8 & 1.9 \\
\hline RCE30 GHB60 & 370 & 238.3 & 628 & 853 & 365 & 59.7 & 1.9 \\
\hline
\end{tabular}

Note: SP is the high-efficiency polycarboxylic acid water reducer.

\subsection{Specimen Casting and Curing Conditions}

The recycled thermal insulation concrete (RTIC) specimens had dimensions of $150 \mathrm{~mm}$ $\times 150 \mathrm{~mm} \times 150 \mathrm{~mm}$ (144 pieces) and $300 \mathrm{~mm} \times 300 \mathrm{~mm} \times 30 \mathrm{~mm}$ (72 pieces) according to the Chinese standard GB/T 50081-2002 [39] and GB/T 10294-2008 [40]. All experimental 
specimens were demolded after $24 \mathrm{~h}$ and maintained for 28 days in a steam curing room with a temperature of $20 \pm 2{ }^{\circ} \mathrm{C}$ and a relative humidity of $95 \%$.

\subsection{Experimental Methods}

\subsubsection{Workability Properties Test}

The workability of recycled thermal insulation concrete based on the coupling influence between GHB and RCE was determined and conducted through the slump and density test according to Chinese standard GB/T50080-2016 [41] and GB/T50080-2002 [42].

\subsubsection{Mechanical Properties Test}

A total of 144 RTIC specimens $(150 \mathrm{~mm} \times 150 \mathrm{~mm} \times 150 \mathrm{~mm})$ were prepared for series experiments of compressive strength (72 pieces) and splitting strength (72 pieces) according to Chinese standard GB/T50081-2002 [39].

\subsubsection{Thermal Insulation Properties Test}

The thermal insulation property of concrete is usually reflected by thermal conductivity. In this paper, a total of 72 specimens ( $300 \mathrm{~mm} \times 300 \mathrm{~mm} \times 30 \mathrm{~mm}$ ) were prepared to determine the thermal conductivity of concrete specimens based on the steady-state and double-plate method (shown in Figure 4).

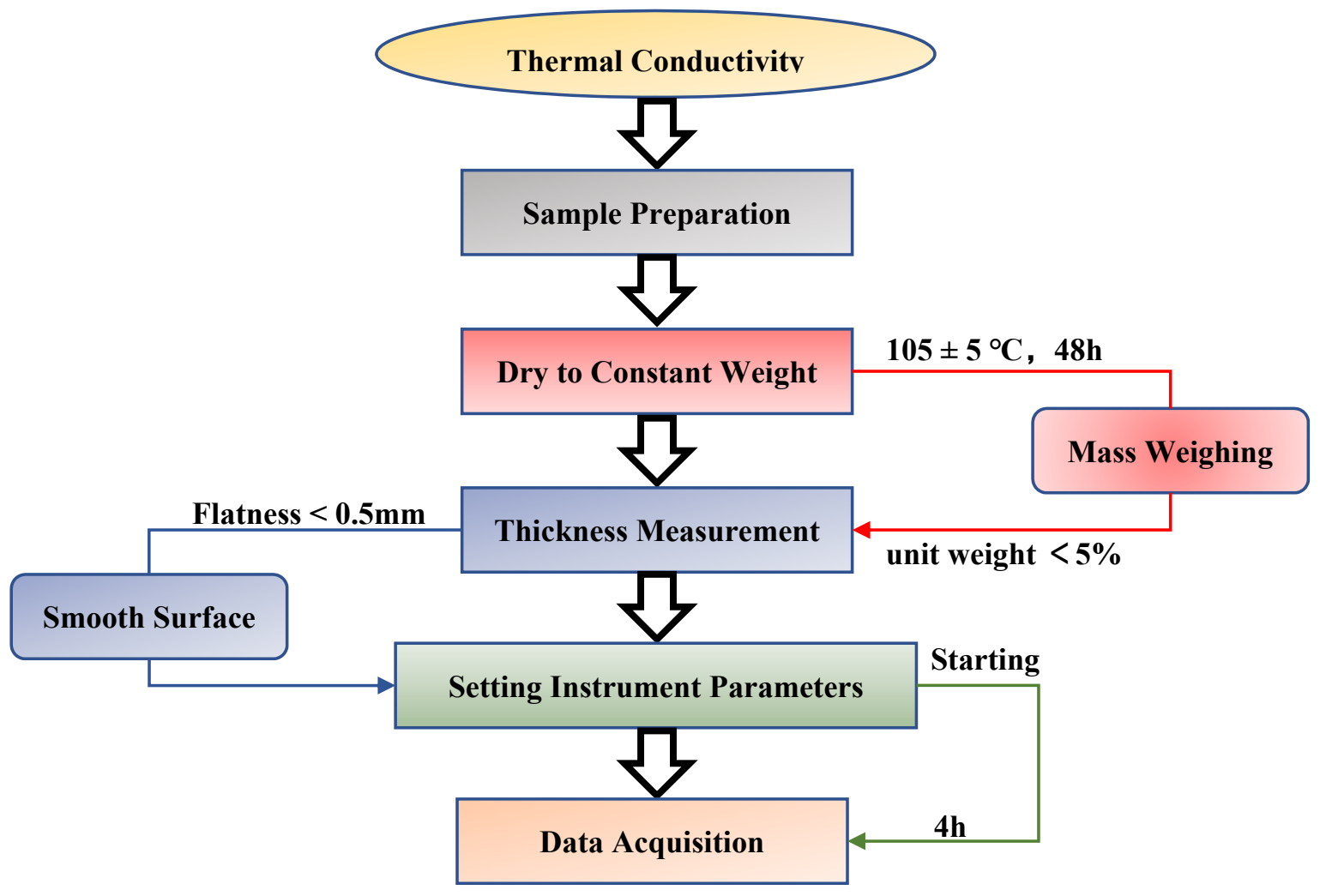

Figure 4. Measurement of thermal conductivity on the RTIC.

\subsubsection{Materials Characterization Tests}

To further explore the effect of RCE and GHB on the mechanical properties and thermal conductivity early performance of recycled thermal insulation concrete, several macro-experimental methods were conducted. A total of 80 experimental samples were subjected to scanning electron microscopy (Hitachi, Shenzhen, China) (SEM, 33 samples), X-ray diffraction (Haoyuan, Dandong, China) (XRD, 24 samples), and Fourier-transform infrared spectroscopy (BRUKER, Shanghai, China) (FTIR, 24 samples) to analyze the changes in the micromorphology, hydration products, and chemical bonding or molecules. 
The preparation and drying conditions of these samples were following Chinese standard GB/T 16594-2008 [43], GB/T 30904-2014 [44], and ISO 19618-2017 [45]. In summary, the experimental flowcharts in this paper are shown in Figure 5.

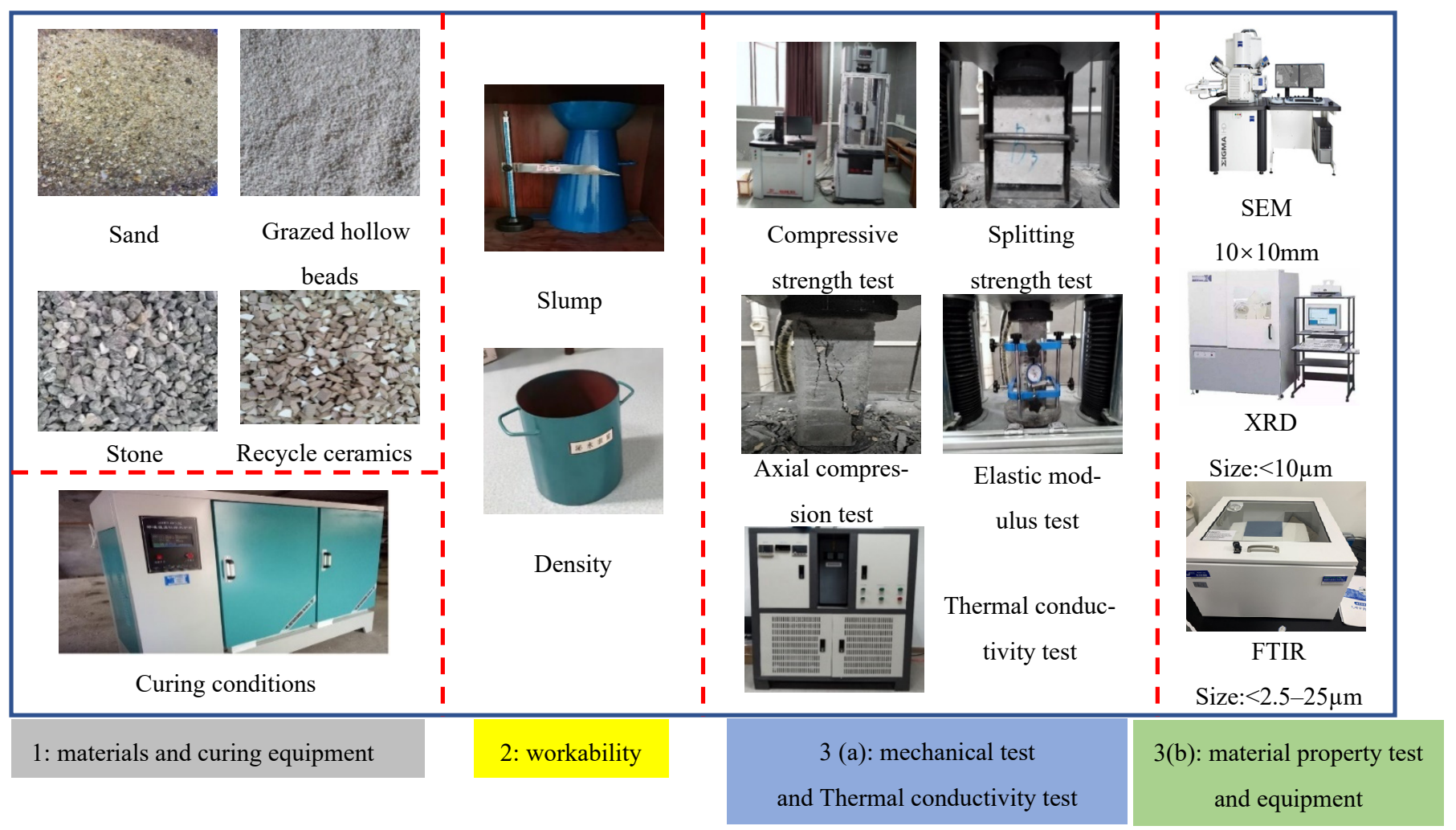

Figure 5. Experimental flowchart.

\section{Results and Discussion}

3.1. Coupled Influence of RCE and GHB on Macroscopic Comprehensive Characteristics of RTIC

In this section, the macroscopic comprehensive performance of RTIC is studied. This section mainly explores the influence of GHB and RCE on the working performance, lightweight performance, mechanical properties and thermal conductivity of RTIC under the coupling effects of different doping amounts.

\subsubsection{Workability and Density Properties of RTIC}

The experimental results and changes of slump subjected to the coupling influence between GHB and RCE on fresh concrete are shown in Figure $6 a, b$. The results showed that, (1) when the content of RCE was constant, the slump degree of concrete increased with the increase of GHB content. Compared with RCE0GHB0 (45 mm), RCE0GHB20 (80 mm), RCE0GHB40 $(110 \mathrm{~mm})$ and RCE0GHB60 $(115 \mathrm{~mm})$ increased by $77.8,144.4$ and $115.6 \%$, respectively. (2) However, when the content of GHB was constant, the influence of RCE on the slump properties of concrete was not obvious. Compared with the reference concrete, the change of collapse degree was 11.1, 1.0 and $-11.1 \%$ within the content range of RCE from 10 to $30 \%$. (3) Similarly, the combined effect of GHB and RCE could better improve the workability performance of RTIC. When the blending contents were RCE0GHB60 $(115 \mathrm{~mm})$ and RCE30GHB60 (115 mm), the material system could obtain the best slump value. (4) The improved workability performance of RTIC was mainly attributed to the influence of GHB. This is because GHB has good water retention properties and can reduce the friction between the aggregates, which can eventually lead to provide the required water phase during the material preparation process. Nevertheless, RCE also has good water absorption, it has little effect on the workability of concrete. This is mainly because 
RCE needs to be pre-wetted in advance to reach saturation, which reduces the effect of improving flow performance. Figure $7 \mathrm{a}, \mathrm{b}$ show the experimental results and changes of density subject to the coupling influence between GHB and RCE on concrete. The results show that: (1) compared with RCE0GHB0, the density of the concrete with the increasing single incorporation of RCE (10 30\%) and GHB (20 60\%) decreased by 1.6, 3.7, 5.3 and $0.8,1.6,2.5 \%$, respectively. (2) RCE has a significant effect on reducing the density of the concrete. Although the density of GHB is much lower than that of natural sand, it absorbs a lot of water during the concrete preparation process, which is not obvious for the reduction of concrete density. (3) In the compound incorporation of GHB and RCE, the negative density change of RCE10GHB20 was the smallest, which had the best combined effect on reducing the density of concrete.

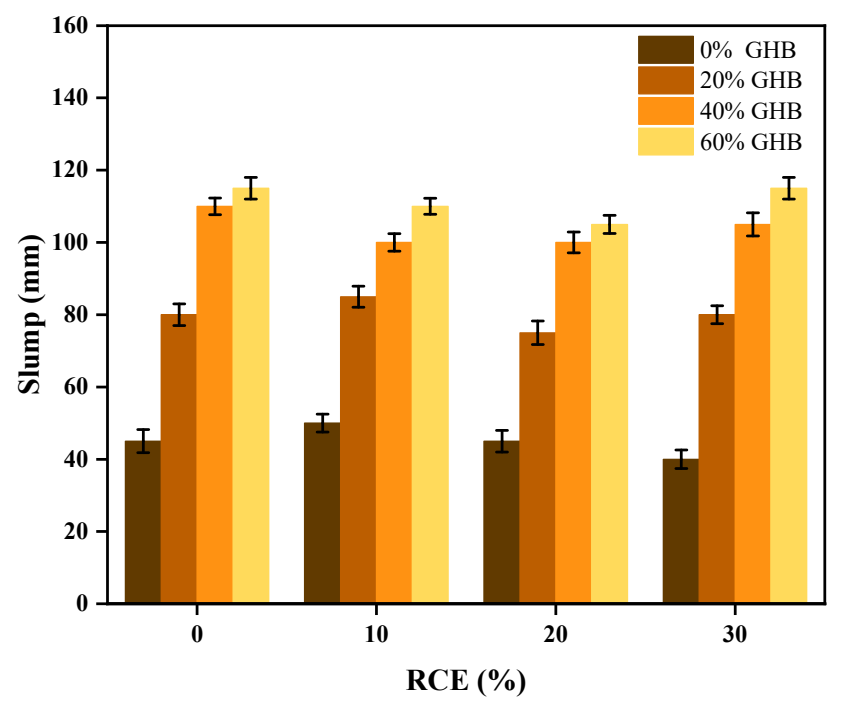

(a)

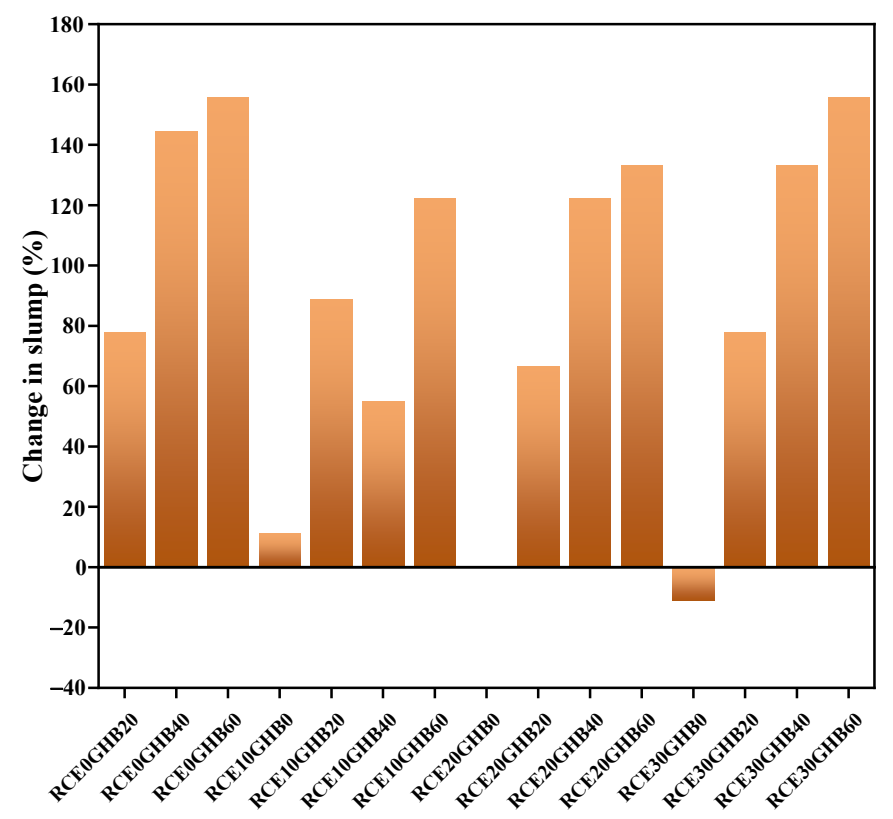

(b)

Figure 6. The experimental results and changes of slump subjected to the coupling influence between GHB and RCE on fresh concrete. (a) The experimental results of slump on fresh concrete; (b) the changes of slump on fresh concrete. 


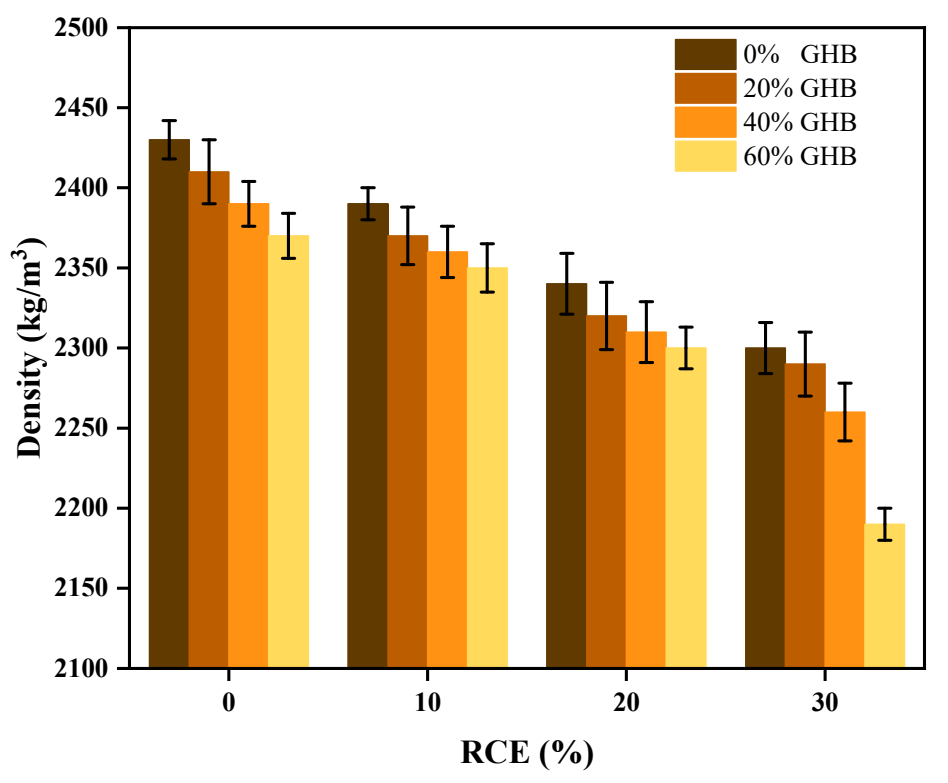

(a)

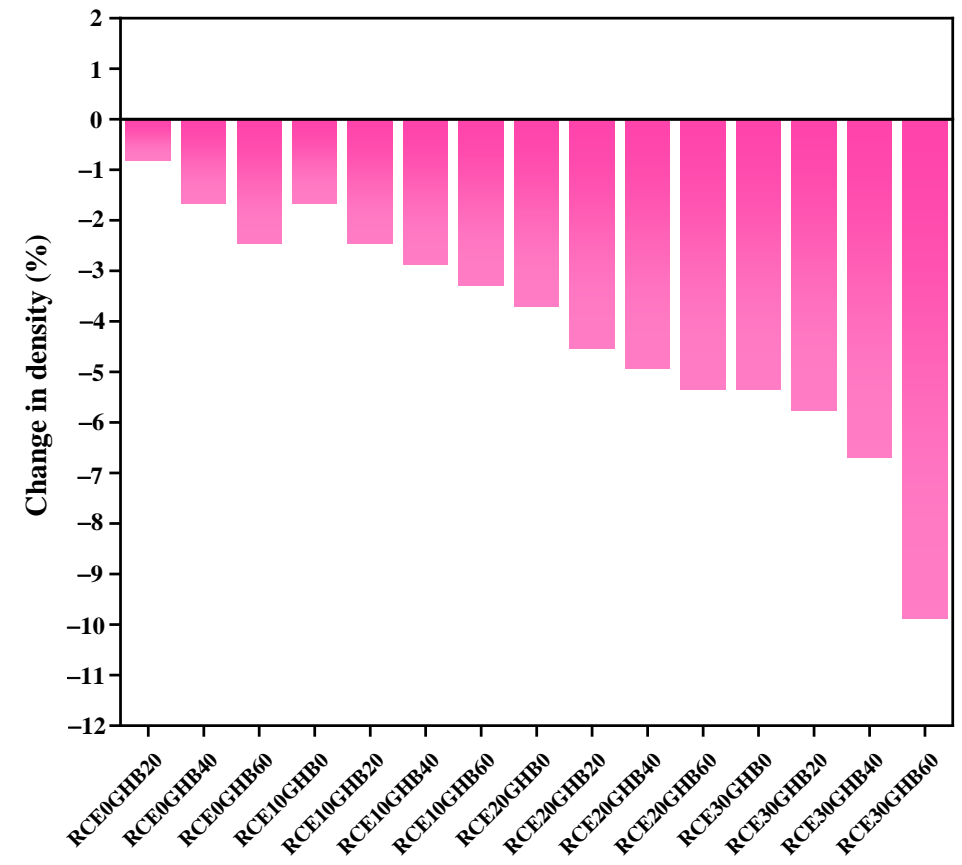

(b)

Figure 7. The experimental results and changes of density subject to the coupling influence between GHB and RCE on RTIC. (a) The experimental results of density on concrete; (b) the changes of density on fresh concrete.

\subsubsection{Analysis of the Compressive Strength of RTIC}

The experimental results and changes of compressive strength are shown in Figure 8a,b. It can be seen that, (1) GHB had a decisive influence on the compressive strength of concrete. Compared with RCE0GHB0, the compressive strength of RCE0GHB20, RCE0GHB40 and RCE0GHB60 decreased by 5.7, 15.6 and 22.7\%, respectively. With the increase of GHB content, the compressive strength of concrete was further reduced. That is because GHB is a brittle material, which is prone to brittle fracture and decomposition due to stress concentration under the action of load, thereby forming more pore defects in the concrete $[46,47]$. In summary, GHB has no significant contribution to the compressive strength 
development of concrete. (2) Furthermore, incorporating ceramic waste aggregate as a partial replacement of natural coarse aggregate also reduced the compressive strength. The compressive strength reduction of RCE10GHB0, RCE20GHB0 and RCE30GHB0 was 5.9, 11.1 and $13.3 \%$ compared with RCE0GHB0. The concrete prepared with RCE was prone to through cracks due to aggregate damage in the process of compressive load failure due to low crush value and porous brittle material properties [7,48,49]. (3) The coupling of GHB and RCE had no positive effect on the compressive strength of RTIC. Comprehensive comparison of the change in compressive strength, RCE30GHB60 had the largest decrease in compressive strength, while RCE10GHB20 had the smallest decrease.

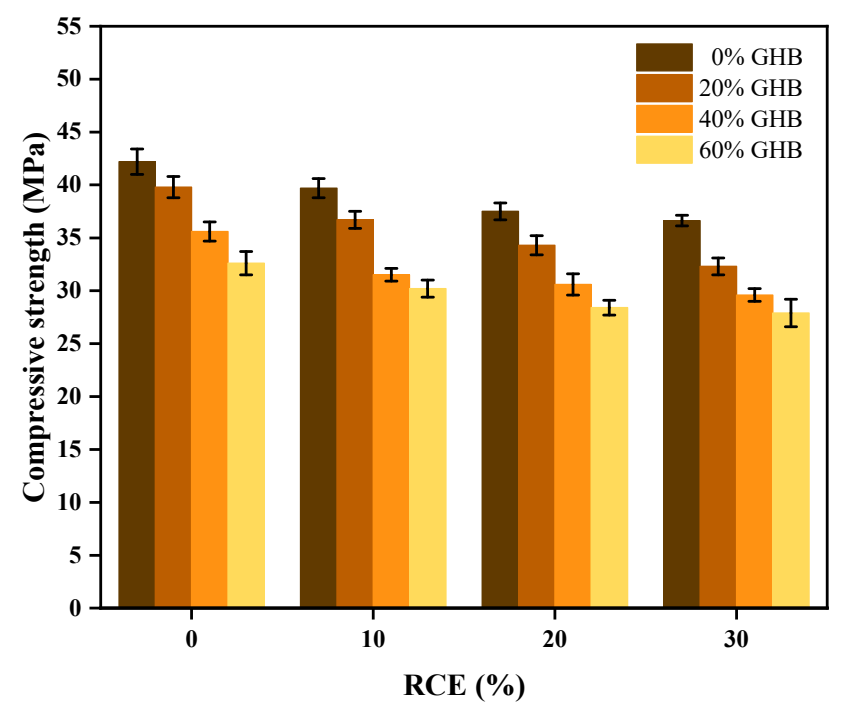

(a)

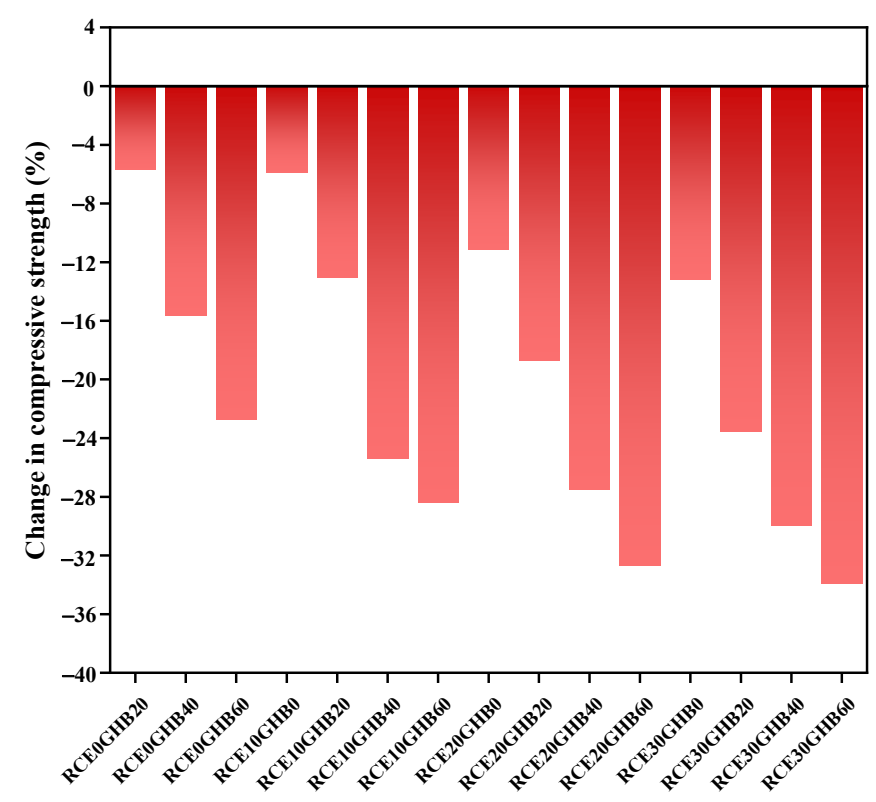

(b)

Figure 8. The experimental results and changes of compressive strength subject to the coupling influence between GHB and RCE on RTIC. (a) The experimental results of compressive strength of RTIC; (b) the changes of compressive strength of RTIC. 


\subsubsection{Analysis on Splitting Tensile Strength of RTIC}

Figure $9 \mathrm{a}, \mathrm{b}$ shows the experimental results and changes of splitting tensile strength of RTIC. Splitting tensile strength decreased significantly with the increase of the incorporation of GHB and RCE. In the process of splitting failure, the GHB and RCE in the concrete deteriorated (even powdery failure) before the natural aggregates. At the same time, the pore structure and micro cracks in the concrete will increase and form more mechanically weak areas, which will eventually lead to a negative impact on the splitting performance of concrete based on the coupling influence between GHB and RCE. In addition, RCE30GHB60 had the largest reduction in split tensile strength $(-1.06 \mathrm{MPa})$, while RCE10GHB20 had the smallest reduction in split tensile strength $(-0.68 \mathrm{MPa})$, which is the best ratio to ensure split tensile performance.

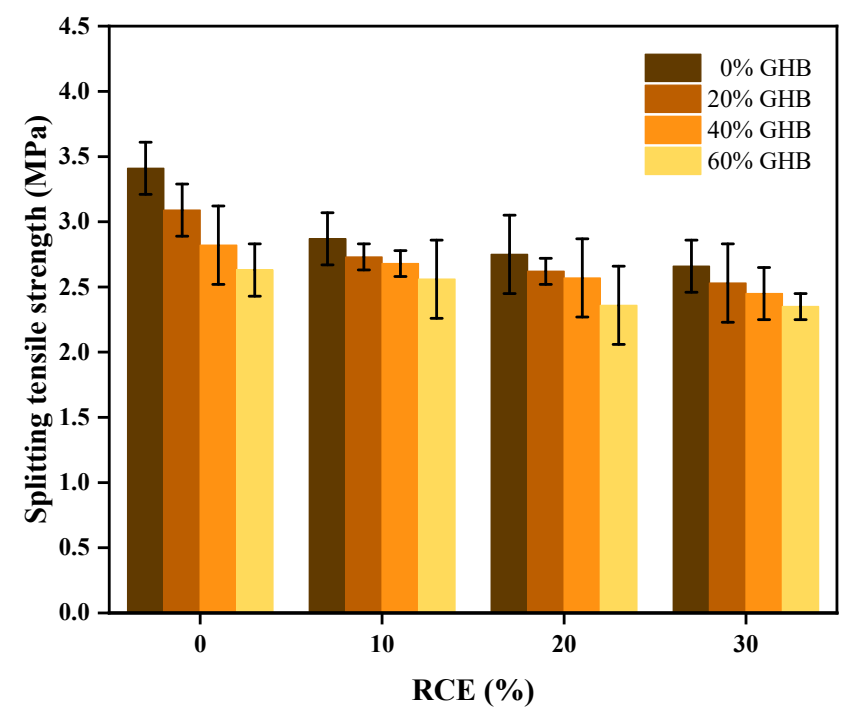

(a)

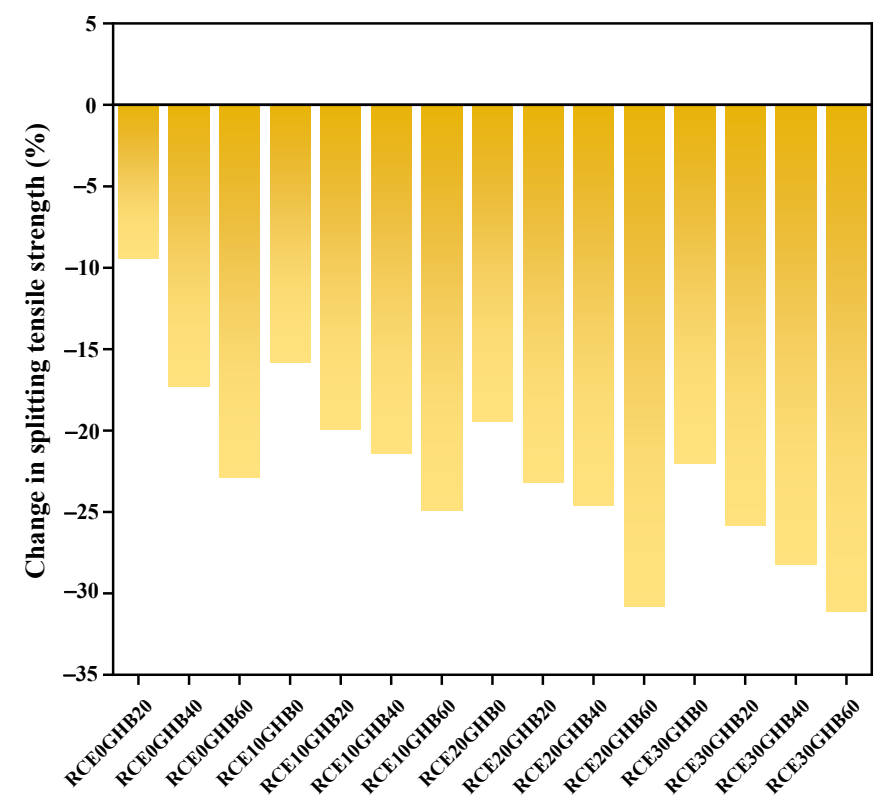

(b)

Figure 9. The experimental results and changes of splitting tensile strength subject to the coupling influence between GHB and RCE on RTIC. (a) The experimental results of splitting tensile strength of RTIC; (b) the changes of splitting tensile strength of RTIC. 


\subsubsection{Insulation Properties of RTIC}

The experimental results and changes of thermal conductivity and insulation property values of RTIC subject to the coupling influence between GHB and RCE are shown in Figure 10a-c. The results show that, (1) the thermal conductivity decreased as the content of GHB increased. When the GHB content was $60 \%$, RTIC had lower thermal conductivity and performance. The significant decrease in thermal conductivity was mainly attributed to the good thermal insulation properties of GHB. When GHB is distributed in concrete, the pore structure and internal spaces are filled with foam material, which hinders the conduction and dispersion of heat, thereby reducing the thermal conductivity of the concrete. (2) However, the thermal conductivity decreased slightly with the increase of RCE, but when RCE and GHB were coupled, the thermal conductivity did not change significantly. This is because the thermal conductivity of ceramics is not significantly different from that of natural coarse aggregates. Compared with natural coarse aggregate, ceramic coarse aggregate has more microcracks, and the porosity of ceramic coarse aggregate is greater than that of ordinary concrete. These factors have a limited influence on reducing the thermal conductivity of concrete. (3) In summary, GHB played a decisive role in reducing the thermal conductivity and improving the thermal insulation performance of RTIC. Considering the mechanical properties and thermal insulation properties of concrete, the mixing amount of RCE is $10-20 \%$, and the mixing amount of GHB is $40-60 \%$.

\subsection{Coupled Influence of RCE and GHB on Material Properties of RTIC}

In order to further explore the modification mechanism of RTIC on the comprehensive properties of concrete, a set of meso-experimental methods to explore the coupled effects of GHB and RCE on RTIC's microstructure, material morphology and key hydration products are discussed in this section.

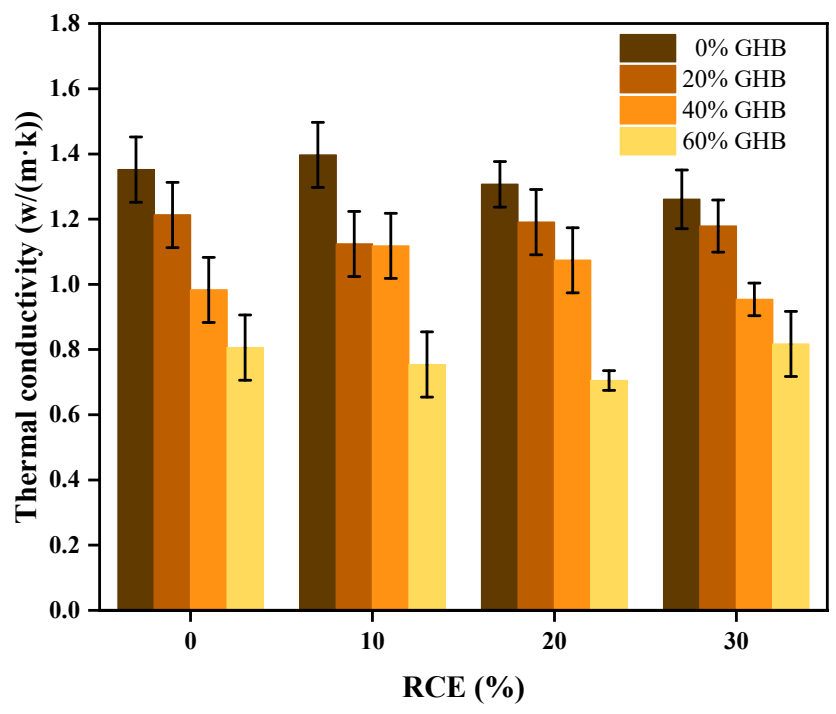

(a)

Figure 10. Cont. 


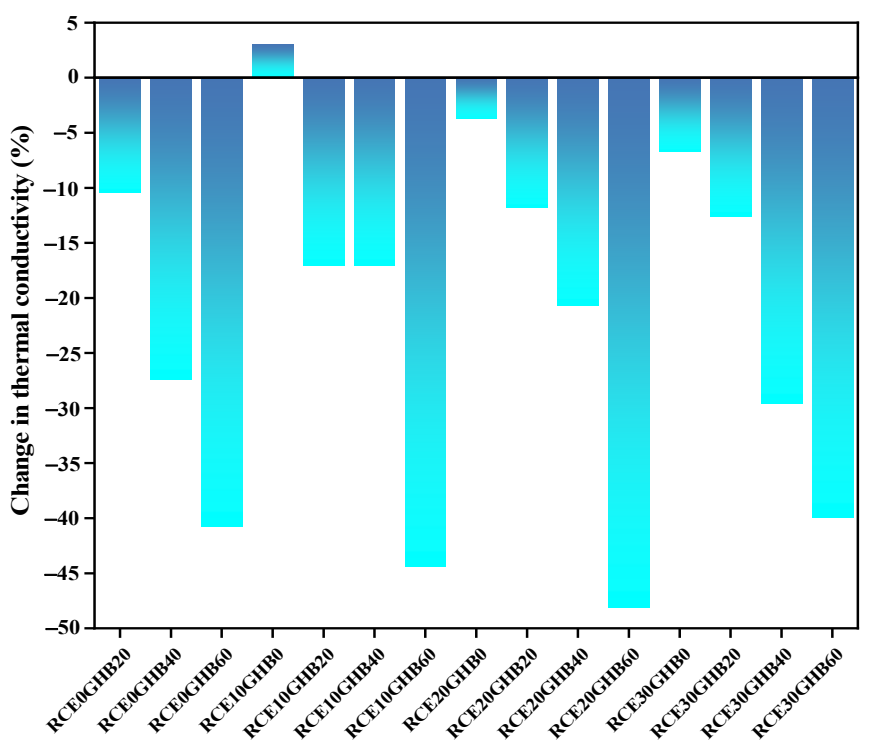

(b)

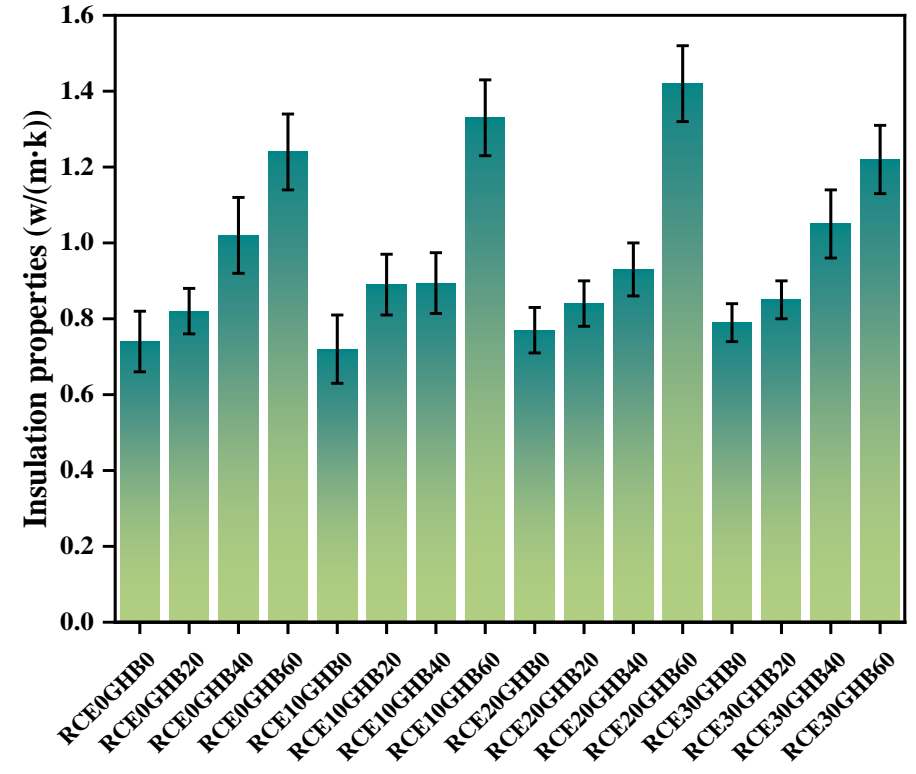

(c)

Figure 10. The experimental results and changes of thermal conductivity and insulation property values of RTIC subject to the coupling influence between GHB and RCE. (a) The experimental results of thermal conductivity of RTIC; (b) the changes of thermal conductivity of RTIC. (c) Insulation property values of RTIC.

\subsubsection{Material Morphology Analysis of RTIC}

The analysis of the material morphology of RTIC is shown in Figure 11. Compared with RCE0GHB0, RCE affected the cured form of C-S-H gel in concrete. As the content of RCE increased, more flocculent C-S-H gels were formed and attached to the surface of the unhydrated cement stone. At the same time, RCE affected the internal spatial distribution of the concrete and caused more microcracks or an increase in obvious pores, which explained why the mechanical properties of the concrete decreased due to the RCE aggregate. In addition, GHB caused unhydrated cement particles to adhere to the surface of $\mathrm{C}-\mathrm{S}-\mathrm{H}$. With the increase in the amount of GHB, the volume and pore size of the pores in the cement stone increased significantly, thereby improving the thermal insulation properties of the concrete, but impairing the mechanical properties. 

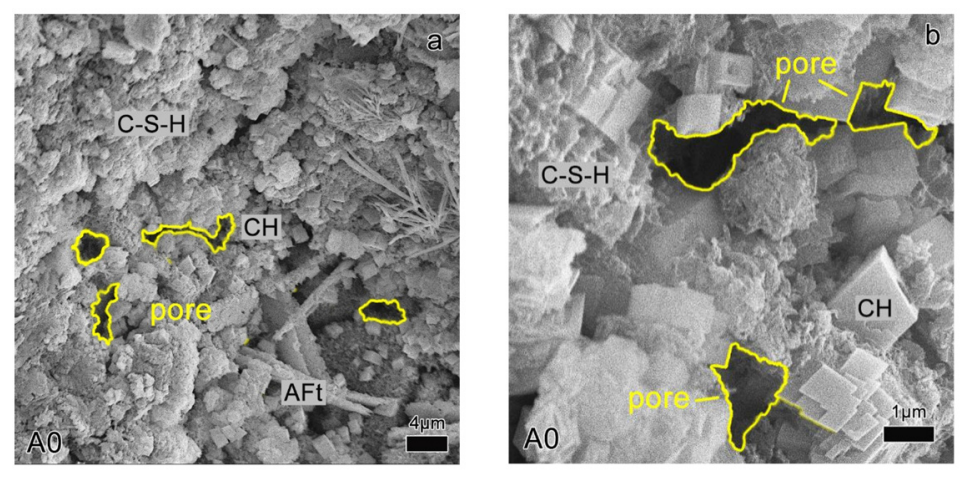

(a)
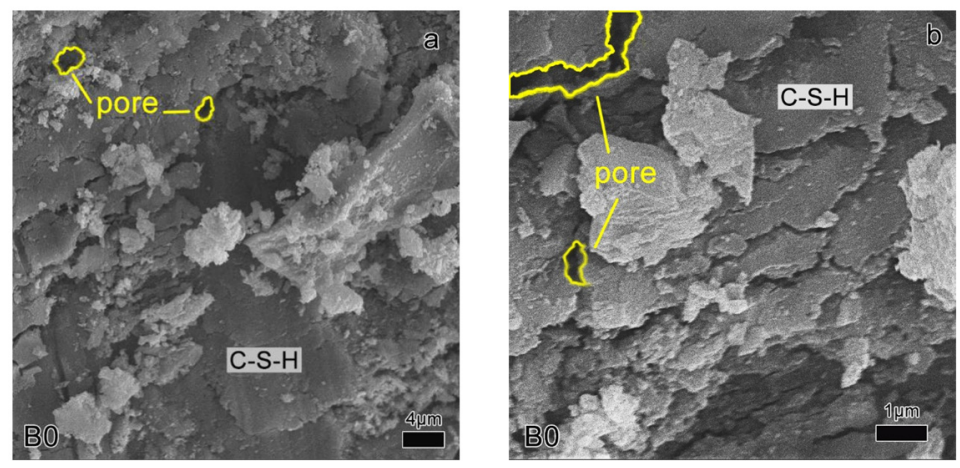

(b)
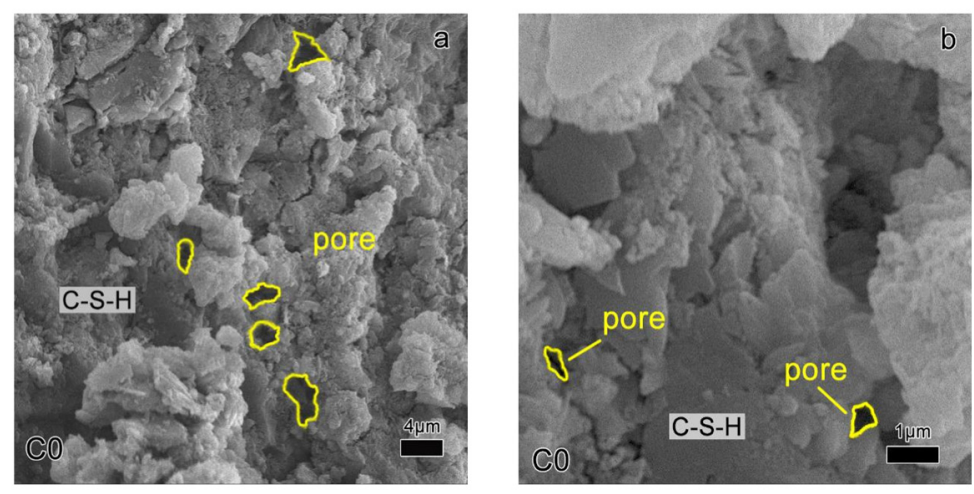

(c)
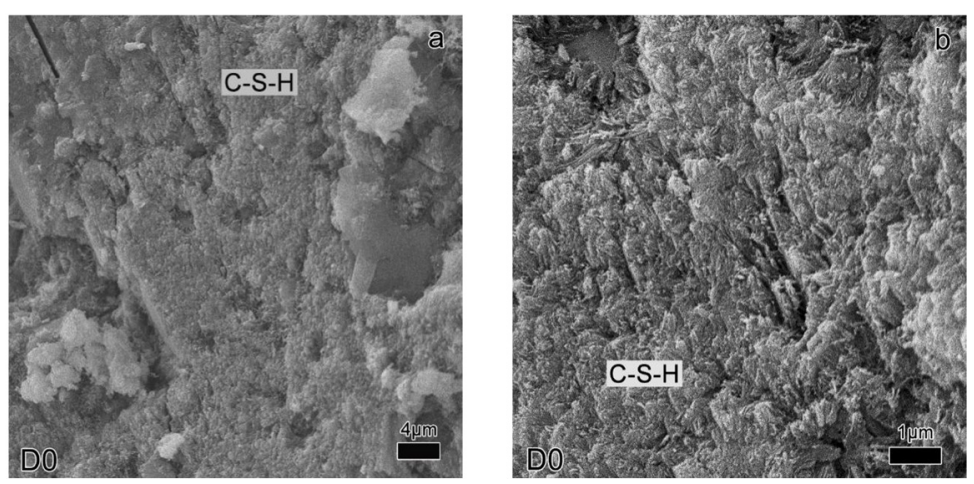

(d)

Figure 11. Cont. 

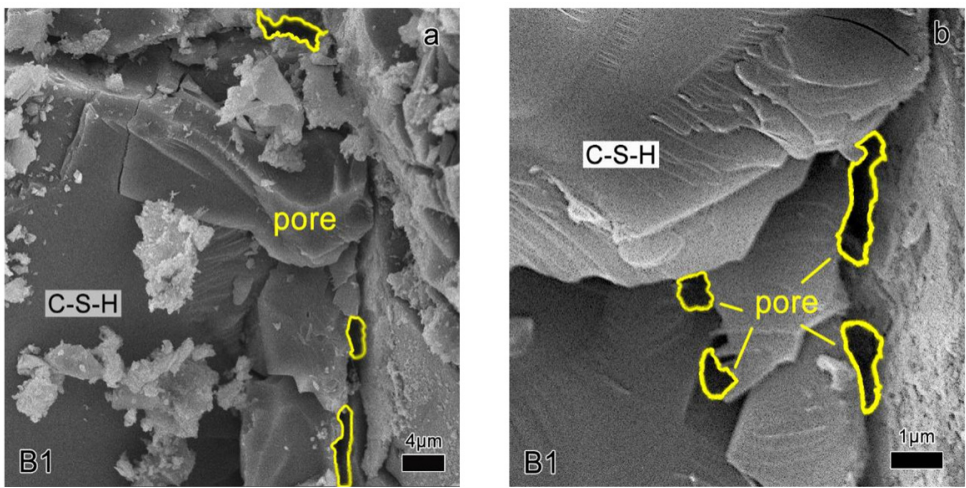

(e)
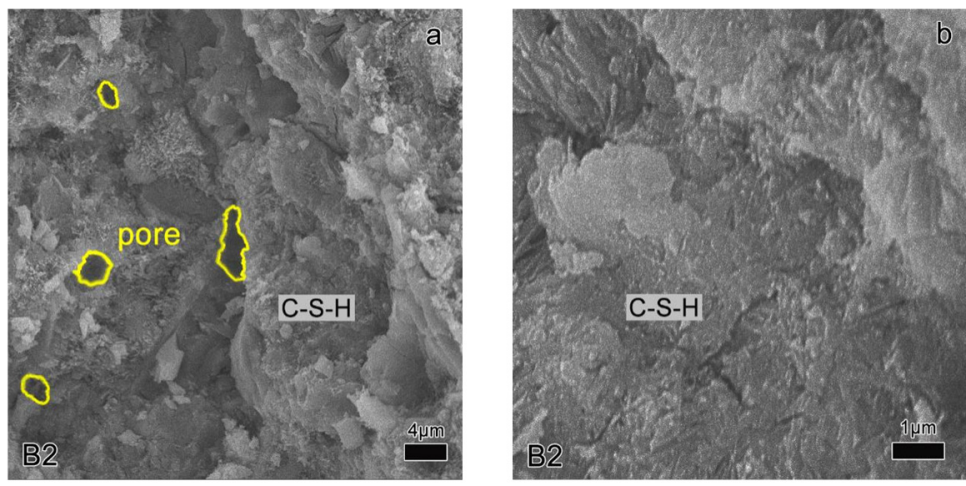

(f)
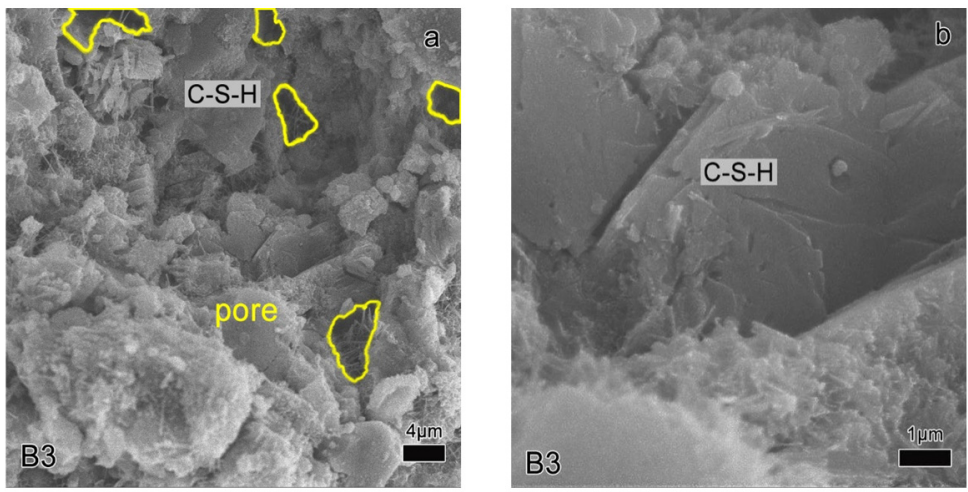

(g)

Figure 11. The analysis of the material morphology of RTIC based on SEM (2.0 $\mathrm{k}$ to 10.0 k). (a) RCE0GHB0; (b) RCE10GHB0; (c) RCE20GHB0; (d) RCE30GHB0; (e) RCE10GHB20; (f) RCE10GHB40; (g) RCE10GHB60.

\subsubsection{Hydration Products Analysis of RTIC}

The experimental results of the crystal composition and hydration products of RTIC are shown in Figure 12. The results show that, (1) with the increase of RCE and GHB, the characteristic peak intensity of hydration products $\mathrm{CH}$ and C-S-H decreased. The increase of RCE and GHB inhibited the formation of the main hydration products in the concrete, which was not conducive to the development of mechanical properties. (2) RCE and GHB had a significant effect on the formation of $\mathrm{CaCO}_{3}$. The increase of $\mathrm{CaCO}_{3}$ leads to premature calcification or aging of concrete, which is very unfavorable to the development of mechanical properties. (3) Further analysis found that GHB had a promoting effect on the formation of Tobermorite. With the increase of GHB, the characteristic peak intensity and 
crystal yield of Tobermorite increased. Tobermorite is a kind of hydrated calcium silicate with high crystallinity. It has strong thermal insulation performance and can improve the thermal insulation performance of concrete. Therefore, with the increase of GHB, the thermal insulation performance of concrete is also enhanced.

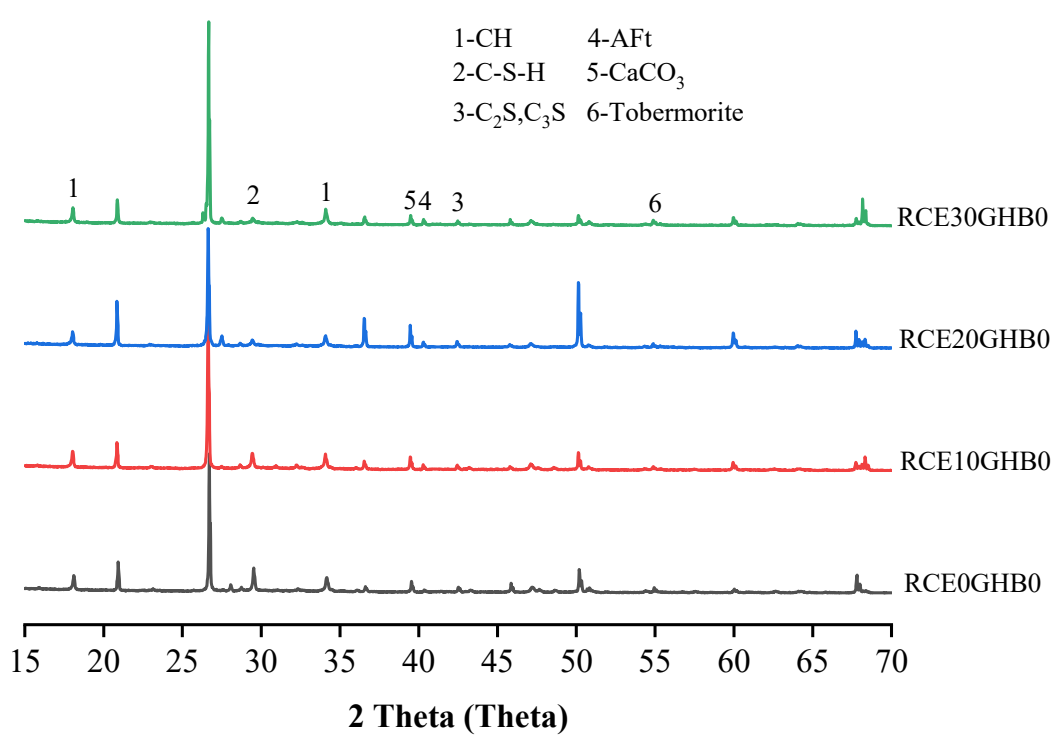

(a)

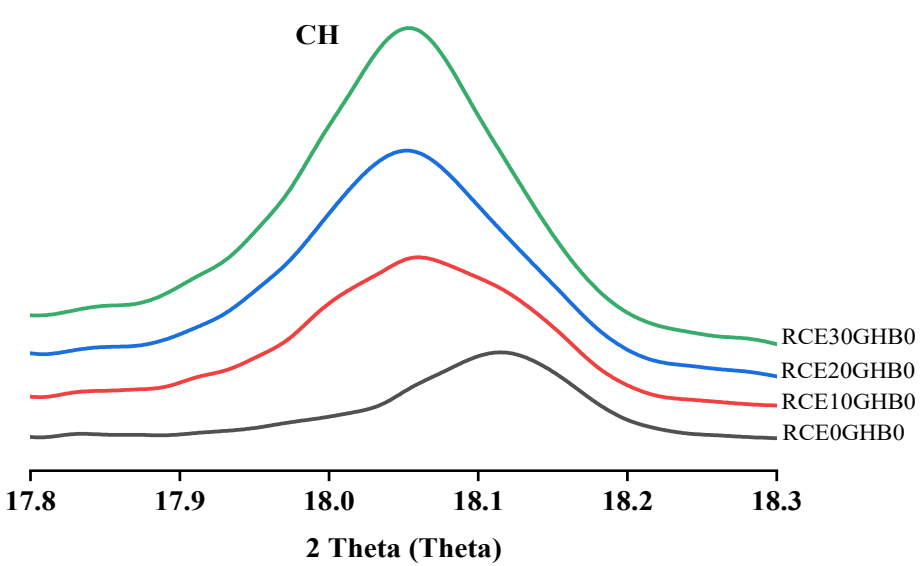

2 Theta (Theta)

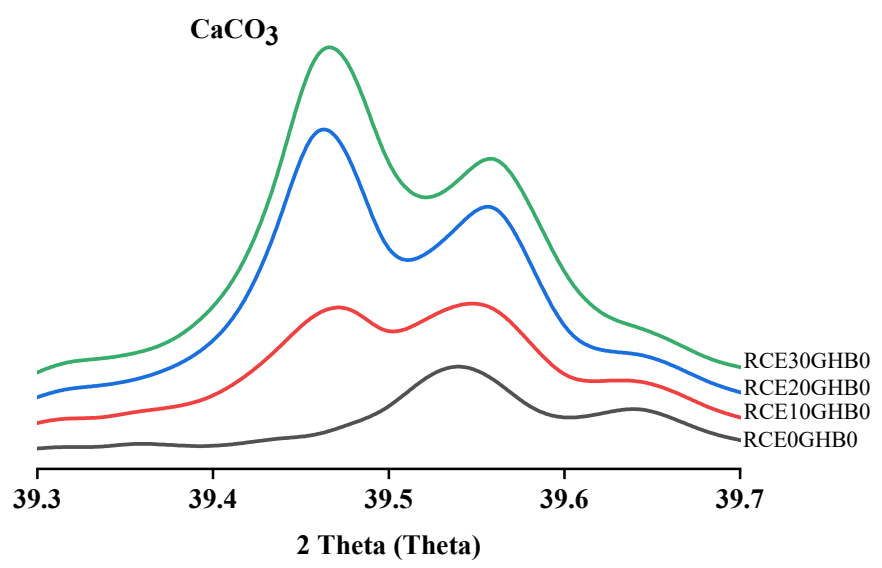

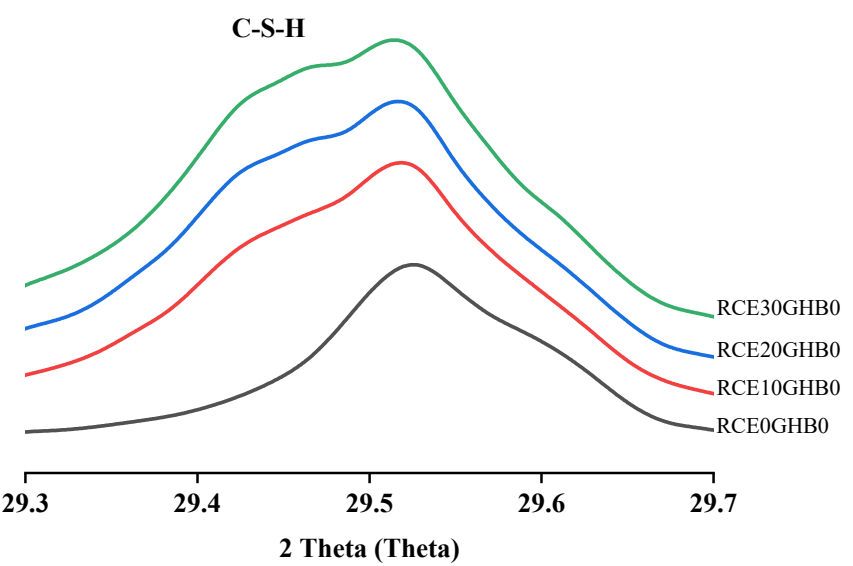

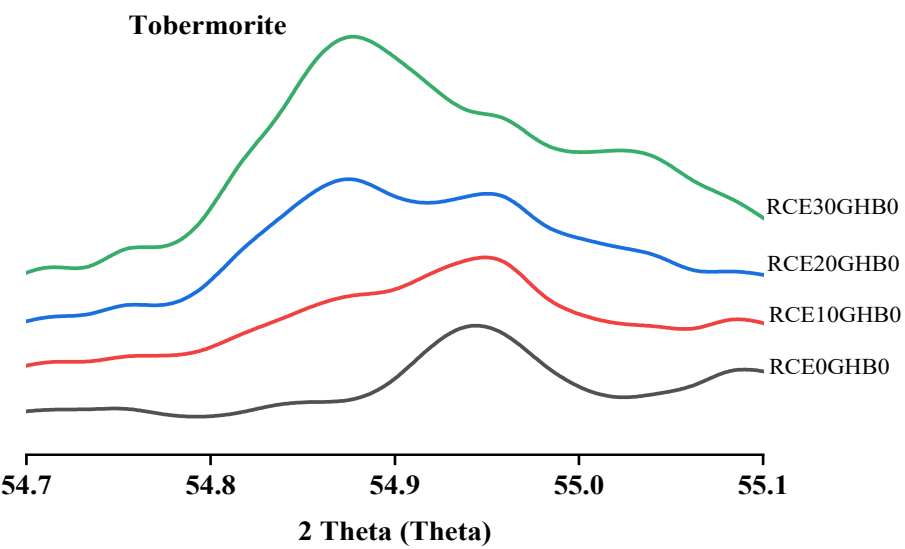

(b)

Figure 12. Cont. 


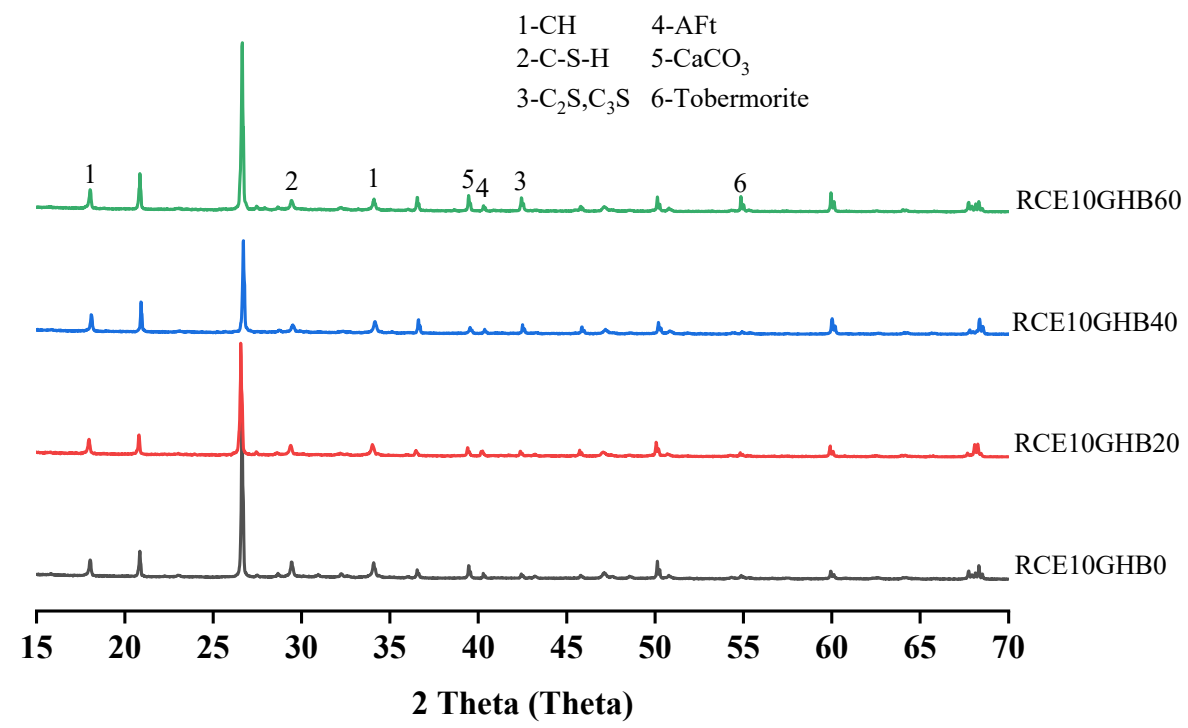

(c)

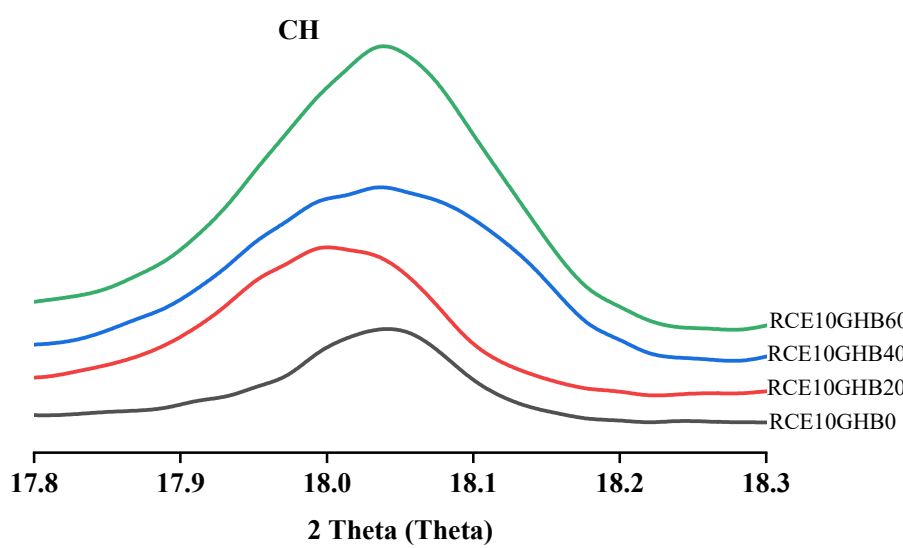

2 Theta (Theta)

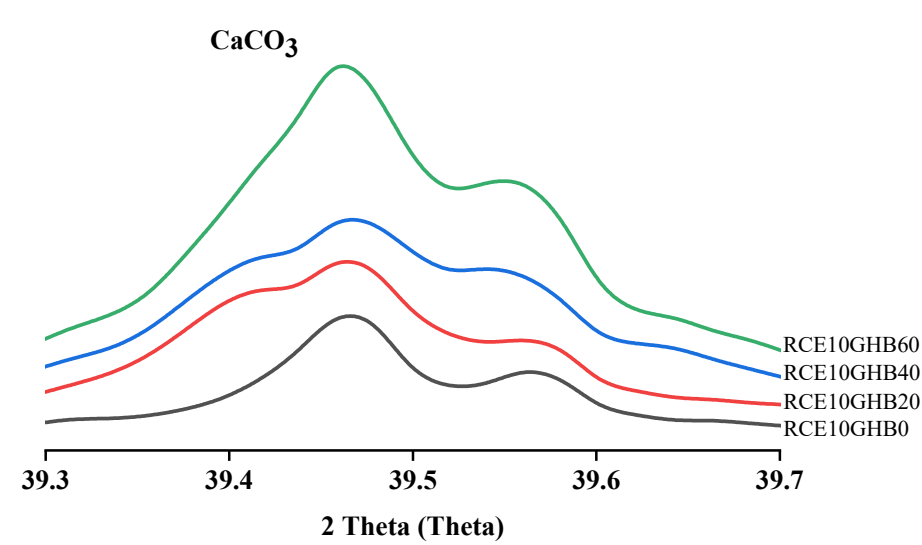

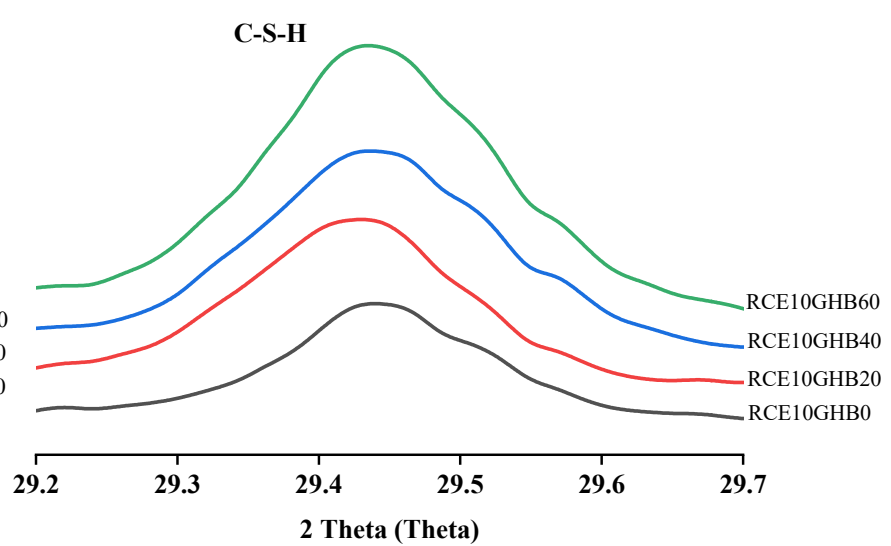

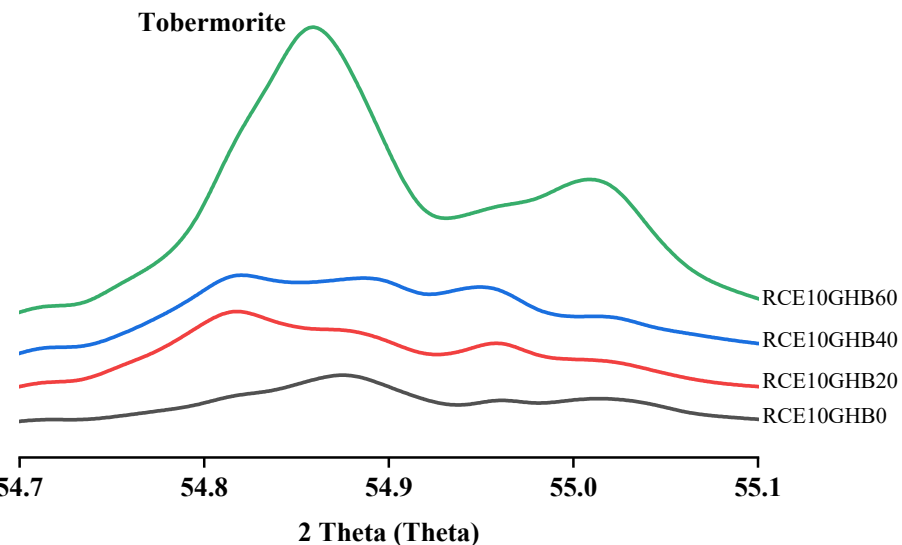

(d)

Figure 12. The experimental results of the crystal composition and hydration products of RTIC based on XRD. (a) The crystal composition and hydration products of RTIC (RCE0GHB0, RCE10GHB0, RCE20GHB0, RCE30GHB0); (b) CH, C-S-H, CaCO 3 , Tobermorite (RCE0GHB0, RCE10GHB0, RCE20GHB0, RCE30GHB0); (c) the crystal composition and hydration products of RTIC (RCE10GHB0, RCE10GHB20, RCE10GHB40, RCE10GHB60); (d) CH, C-S-H, CaCO 3 , Tobermorite (RCE10GHB0, RCE10GHB20, RCE10GHB40, RCE10GHB60). 


\subsubsection{Functional Group Changes of RCTIC}

The effect of RCE and GHB on the functional groups of concrete hydration products is shown in Figure 13. The shrinkage vibration of $\mathrm{H}-\mathrm{O}-\mathrm{H}$ (3400) functional group and the bending vibration of H-O-H (1640) significantly changed with the increasing content of RCE and GHB. H-O-H (3400) functional group had a more pronounced oscillation range, because RCE and GHB have high water absorption and can store a large amount of water phase. At the same time, the shrinkage vibration of the $-\mathrm{OH}$ (3637) functional group in $\mathrm{CH}$ increased significantly with the content of RCE and GHB based on the influence of $\mathrm{CaCO}_{3}$ production in concrete.

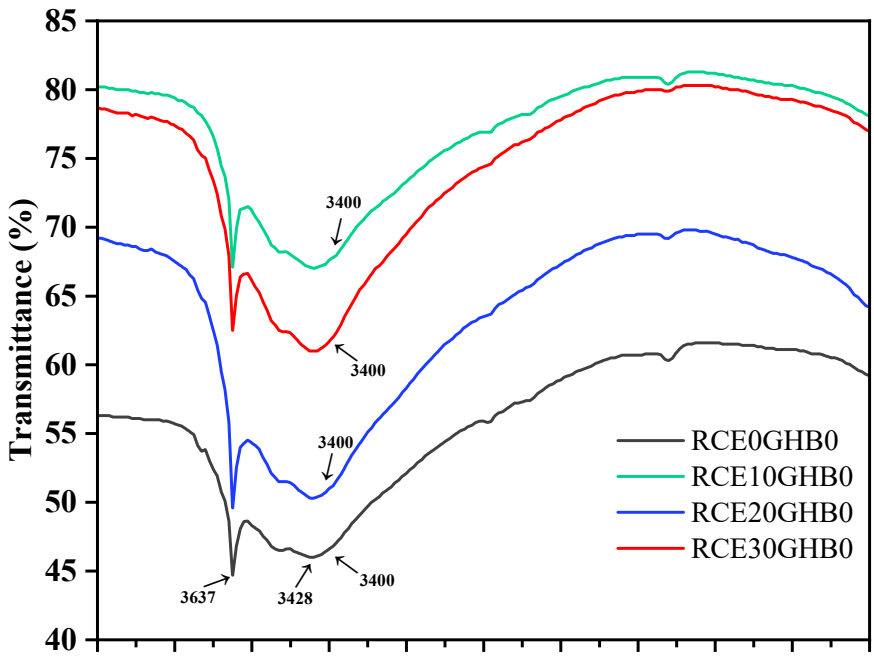

40003800360034003200300028002600240022002000

Wavenumbers $\left(\mathrm{cm}^{-1}\right)$

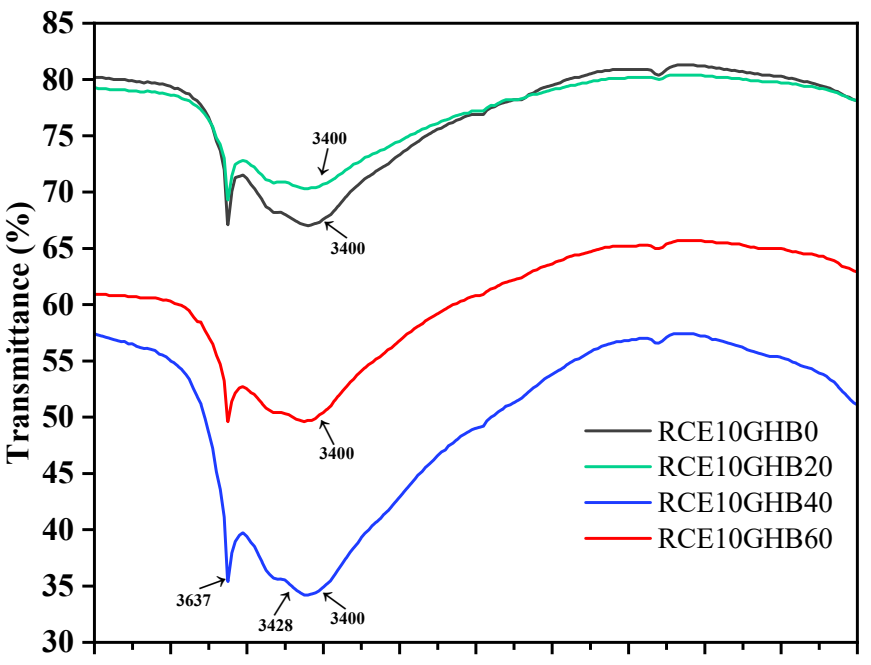

40003800360034003200300028002600240022002000

Wavenumbers $\left(\mathrm{cm}^{-1}\right)$

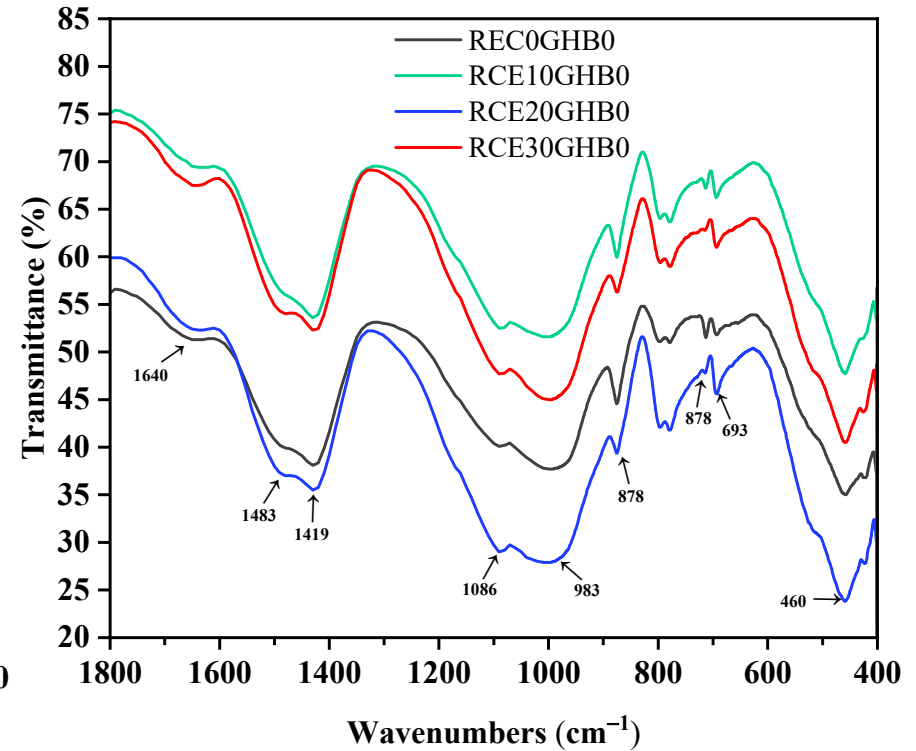

(a)

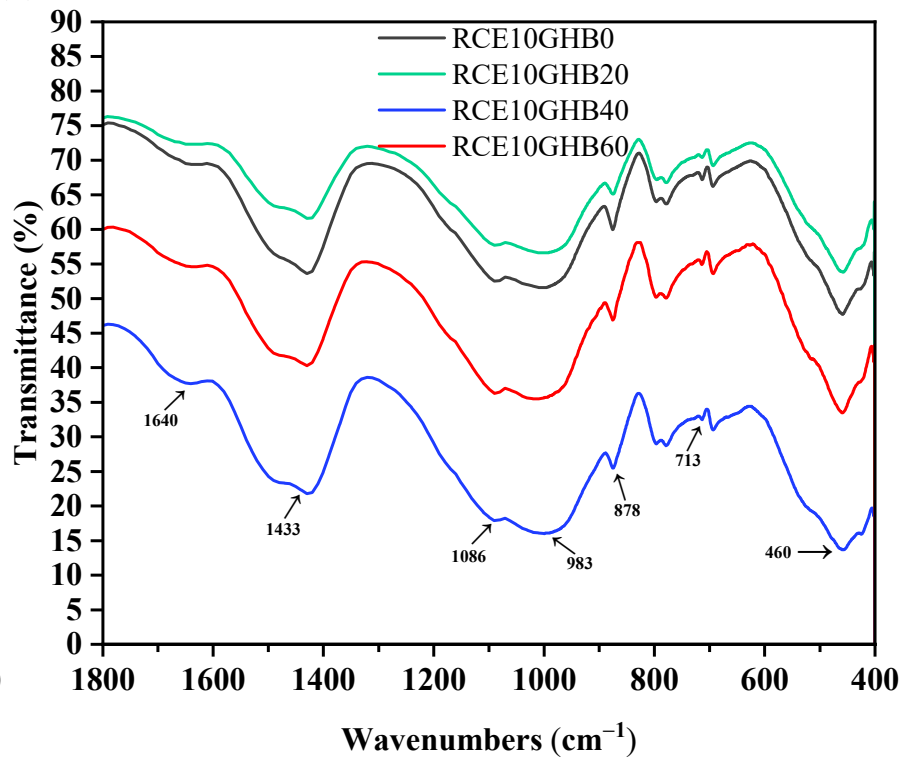

(b)

Figure 13. The effect of RCE and GHB on the functional groups of concrete hydration products. (a) The functional groups of RTIC (RCE0GHB0, RCE10GHB0, RCE20GHB0, RCE30GHB0); (b) the functional groups of RTIC (RCE10GHB0, RCE10GHB20, RCE10GHB40, RCE10GHB60). 


\subsection{Mathematical Representation of the Coupled Influence of RCE and GHB}

The effects of RCE and GHB on RTIC workability, compressive strength, splitting tensile strength and insulation properties can be quantitatively determined by the correlation principle. The interaction between these two parameters is determined as follows:

$$
\begin{gathered}
k_{1}=\frac{\text { Slump }[\text { Combined RCE and GHB Content }]}{\text { Slump }[\text { Control Group }]} \\
k_{2}=\frac{\text { Compressive strength }[\text { Combined RCE and GHB Content }]}{\text { Compressivestrength }[\text { Control Group }]} \\
k_{3}=\frac{\text { Splitting tensile strength }[\text { Combined } R \text { CE and GHB Content }]}{\text { Splitting tensile strength }[\text { Control Group }]} \\
k_{4}=\frac{\text { Insulation properties }[\text { Combined RCE and GHB Content }]}{\text { Insulation properties }[\text { Control Group }]} \\
K=\Re_{1} k_{1}+\Re_{2} k_{2}+\Re_{3} k_{3}+\Re_{4} k_{4}
\end{gathered}
$$

where $k_{1}$ is the coefficient of the influence on liquidity, $k_{2}$ is the coefficient of influence on compressive strength, $k_{3}$ is the coefficient of influence on splitting tensile strength, $k_{4}$ is the coefficient of influence on insulation, $\Re$ is the correlation parameter between RCE and GHB content, $K$ is the quantitative characterization of the coupled effects of RCE and GHB content on concrete comprehensive characteristics.

The calculation results of the influence coefficient of RCE and GHB on concrete performance are shown in Figure 14. The following conclusions can be reached. (1) Considering the mechanical properties and thermal insulation properties of concrete, the best content of RTIC is RCE10GHB60. (2) The allowable content of GHB used for general engineering needs can be relaxed in order to improve thermal insulation performance while ensuring the quality of the concrete. (3) The content of RCE needs to be strictly controlled, and its reasonable replacement rate should not exceed $20 \%$ of the natural coarse aggregate.
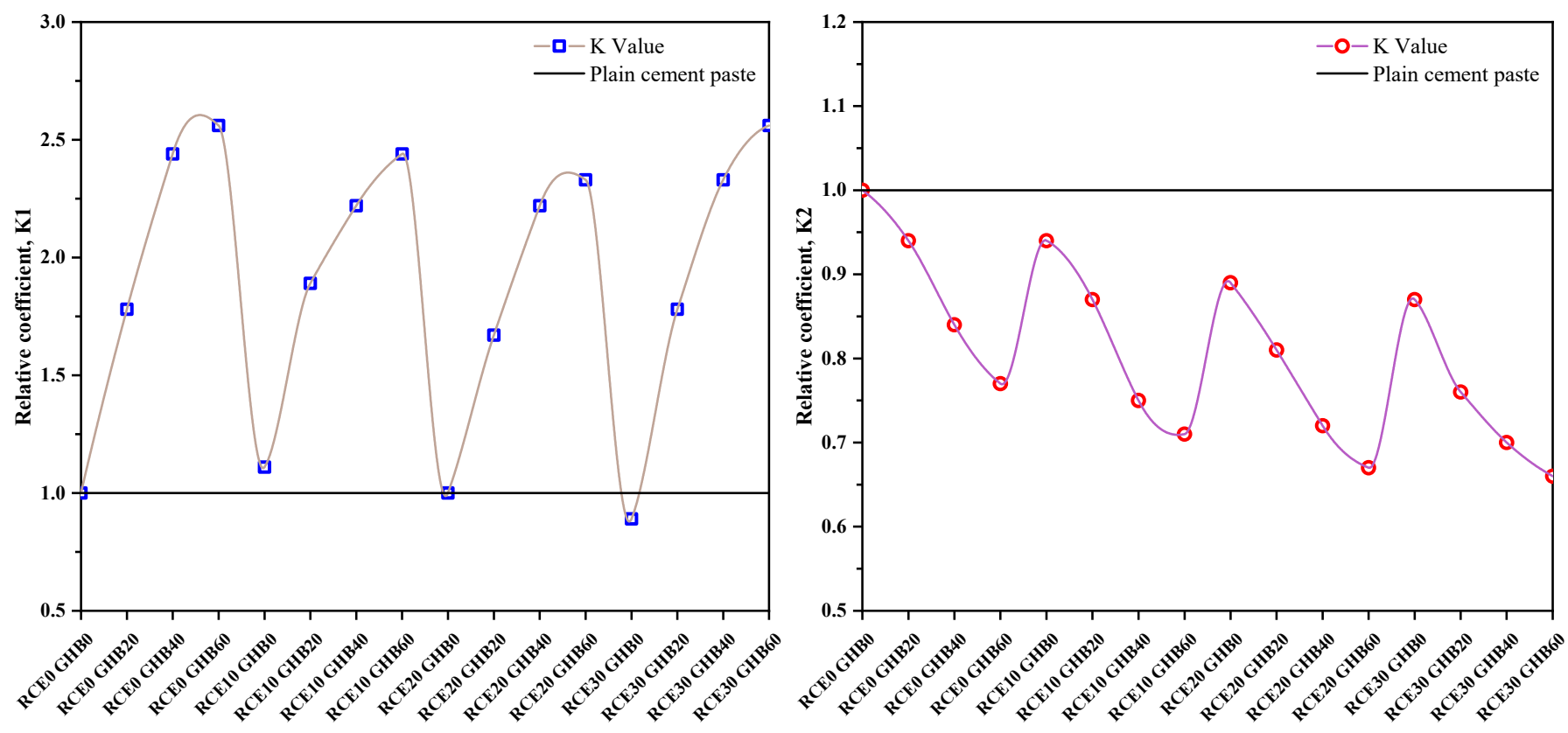

Figure 14. Cont. 

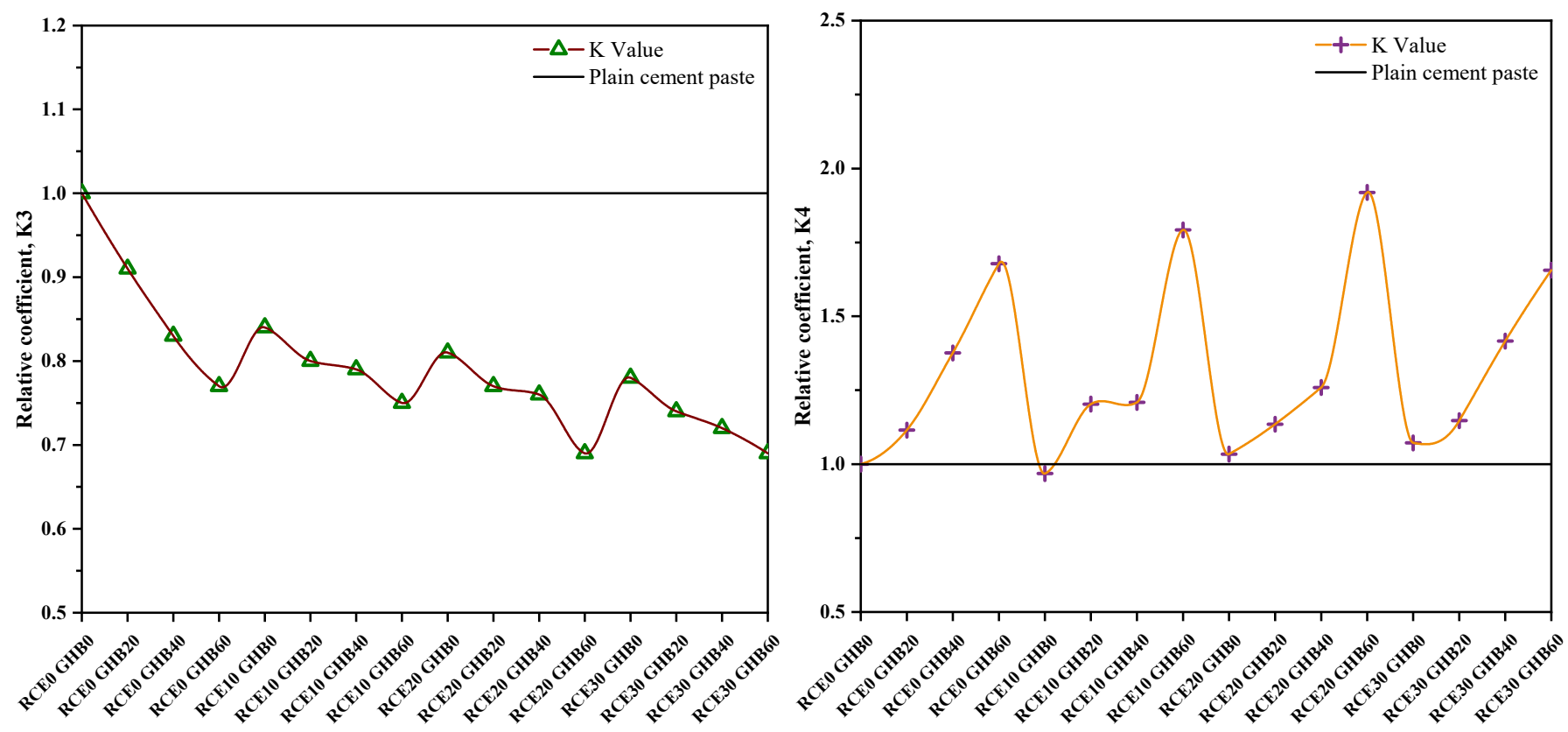

(a)

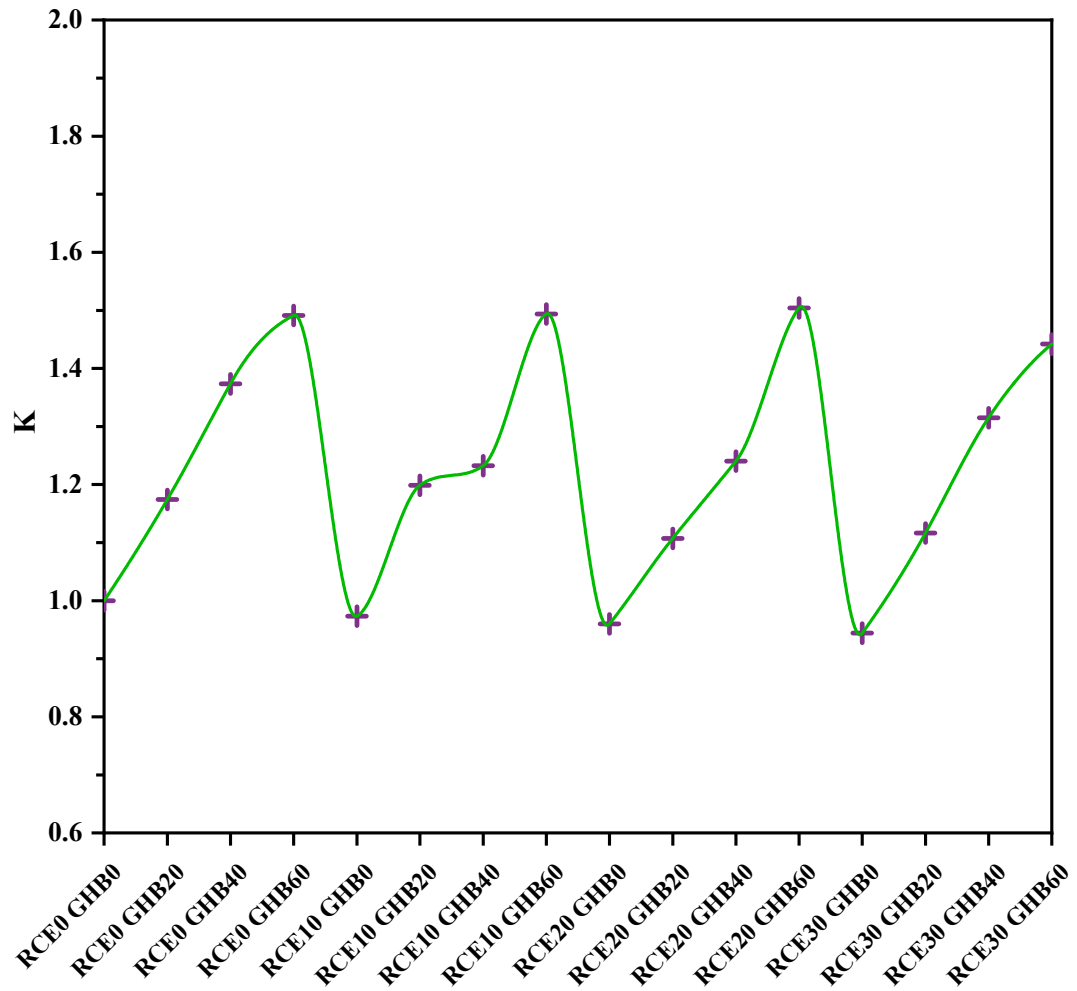

(b)

Figure 14. The calculation results of the influence coefficient of RCE and GHB on concrete performance. (a) K1, K2, K3, K4. (b) K.

\section{Conclusions}

This paper investigated the influence of RCE and GHB on the mechanical, thermal conductivity and material properties of concrete, and the following conclusions can be drawn: 
1. RCE can inhibit the density and mechanical properties of RTIC, but it has little effect on the working and thermal insulation properties of RTIC. GHB can improve the workability and insulation properties of RTIC (155.6 and 91.9\% maximum increase), but decreases the density and mechanical properties (9.9 and 33.9\% maximum decrease).

2. The incorporation of GHB and RCE inhibited the formation of $\mathrm{CH}$ and C-S-H and promoted the increase of $\mathrm{CaCO}_{3}$, which was detrimental to the macroscopic mechanical properties of RTIC. Meanwhile, the increase in GHB led to an increase in the production of Tobermorite, which largely improves the insulation properties of RTIC.

3. GHB and RCE can be used to prepare regenerated thermal insulation concrete due to the synergistic development of mechanical properties and thermal insulation properties. It is considered that $10 \% \mathrm{RCE}$ and $60 \% \mathrm{GHB}$ are the best doping amounts. The new thermal insulation concrete material prepared based on this material design system can be used in practical projects such as prefabricated roof structures in civil engineering, special transportation pipelines, and link bridges in equipment and accessory buildings.

4. GHB and RCE can be used to prepare regenerated thermal insulation concrete due to the synergistic development of mechanical properties and thermal insulation properties. It is considered that 10\% RCE and $60 \% \mathrm{GHB}$ are the best doping amounts.

Author Contributions: Conceptualization, Y.Y. and B.L.; methodology, B.L.; software, Y.Y.; validation, Y.Y., B.L.; formal analysis, Y.Y.; investigation, D.L.; resources, D.L.; data curation, Y.Y. and B.L.; writing-original draft preparation, Y.Y.; writing - review and editing, Y.Y. and B.L.; visualization, Y.Y.; supervision, B.L.; project administration, B.L.; funding acquisition, D.L. All authors have read and agreed to the published version of the manuscript.

Funding: This research was funded by the Science and Technology Innovation Platform of Foshan City (Grant No. 2016AG100341, Guangdong Province, China).

Institutional Review Board Statement: Not applicable.

Informed Consent Statement: Not applicable.

Data Availability Statement: Data available on request due to restrictions eg privacy or ethical.

Conflicts of Interest: We declare that we have no financial and personal relationships with other people or organizations that can inappropriately influence our work, there is no professional or other personal interest of any nature or kind in any product, service and/or company that could be construed as influencing the position presented in, or the review of, the manuscript entitled, "Coupling influence between recycled ceramics and grazed hollow beads on mechanical properties and thermal conductivity of recycled thermal insulation concrete".

\section{References}

1. Ogawa, Y.; Bui, P.T.; Kawai, K.; Sato, R. Effects of porous ceramic roof tile waste aggregate on strength development and carbonation resistance of steam-cured fly ash concrete. Constr. Build. Mater. 2020, 236, 117462. [CrossRef]

2. Siddique, S.; Shrivastava, S.; Chaudhary, S. Durability properties of bone china ceramic fine aggregate concrete. Constr. Build. Mater. 2018, 173, 323-331. [CrossRef]

3. Luo, W. Analysis of Strengthening the Application of External Wall Insulation Materials in Green Building Energy Saving Project. Insight-Mater. Sci. 2020, 3, 32-35. [CrossRef]

4. Kumar, P. Self-compacting concrete: Methods of testing and design. J. Inst. Eng. India Civ. Eng. Div. 2006, 86, 145-150.

5. Mo, K.H.; Alengaram, U.J.; Jumaat, M.Z.; Yap, S.P. Feasibility study of high volume slag as cement replacement for sustainable structural lightweight oil palm shell concrete. J. Clean. Prod. 2015, 91, 297-304. [CrossRef]

6. Manfredi, S.; Pant, R.; Pennington, D.W.; Versmann, A. Supporting environmentally sound decisions for waste management with LCT and LCA. Int. J. Life Cycle Assess. 2011, 16, 937-939. [CrossRef]

7. Nepomuceno, M.C.; Isidoro, R.A.; Catarino, J.P. Mechanical performance evaluation of concrete made with recycled ceramic coarse aggregates from industrial brick waste. Constr. Build. Mater. 2018, 165, 284-294. [CrossRef]

8. Bao, Z.; Lu, W.; Chi, B.; Yuan, H.; Hao, J. Procurement innovation for a circular economy of construction and demolition waste: Lessons learnt from Suzhou, China. Waste Manag. 2019, 99, 12-21. [CrossRef] 
9. El-Fadel, M.; Findikakis, A.N.; Leckie, J.O. Environmental impacts of solid waste landfilling. J. Environ. Manag. 1997, 50, 1-25. [CrossRef]

10. Greenstone, M.; Hanna, R. Environmental regulations, air and water pollution, and infant mortality in India. Am. Econ. Rev. 2014, 104, 3038-3072. [CrossRef]

11. Anderson, D.J.; Smith, S.T.; Au, F.T. Mechanical properties of concrete utilising waste ceramic as coarse aggregate. Constr. Build. Mater. 2016, 117, 20-28. [CrossRef]

12. Mehta, P.K.; Meryman, H. Tools for reducing carbon emissions due to cement consumption. Structure 2009, 1, 11-15.

13. Flower, D.J.; Sanjayan, J.G. Green house gas emissions due to concrete manufacture. Int. J. Life Cycle Assess. 2007, 12, 282-288. [CrossRef]

14. Rashad, A.M.; Sadek, D.M.; Hassan, H.A. An investigation on blast-furnace stag as fine aggregate in alkali-activated slag mortars subjected to elevated temperatures. J. Clean. Prod. 2016, 112, 1086-1096. [CrossRef]

15. Batayneh, M.; Marie, I.; Asi, I. Use of selected waste materials in concrete mixes. Waste Manag. 2007, 27, 1870-1876. [CrossRef]

16. Ostrowski, K.; Stefaniuk, D.; Sadowski, Ł.; Krzywiński, K.; Gicala, M.; Różańska, M. Potential use of granite waste sourced from rock processing for the application as coarse aggregate in high-performance self-compacting concrete. Constr. Build. Mater. 2020, 238, 117794. [CrossRef]

17. Zeng, Y.; He, Z.; Li, M. Core-shell structured monodisperse carbon-rich $\mathrm{SiO}_{1 \cdot 31} \mathrm{C}_{1.46} \mathrm{H}_{0.81}$ ceramic spheres as anodes for highcapacity lithium-ion batteries. Nanotechnology 2021, 32, 190002. [CrossRef]

18. Chen, T.; Wang, H.; Su, W.; Wang, X.; Mehmood, F.; Zhang, K.; Huo, T.; Wang, C. Thermoelectric performance of Dy/Y co-doped $\mathrm{SrTiO}_{3}$ ceramic composites with submicron $\mathrm{A}_{2} \mathrm{Ti}_{2} \mathrm{O}_{7}(\mathrm{~A}=$ Dy, $\mathrm{Y})$ pyrochlore. J. Phys. D Appl. Phys. 2021, 54, 155501.

19. Ge, Q.; Gu, D.; Dai, D.; Ma, C.; Sun, Y.; Shi, X.; Li, Y.; Zhang, H.; Chen, H. Mechanisms of laser energy absorption and melting behavior during selective laser melting of titanium-matrix composite: Role of ceramic addition. J. Phys. D Appl. Phys. 2021, 54, 115103. [CrossRef]

20. Li, L.G.; Ouyang, Y.; Zhuo, Z.Y.; Kwan, A.K.H. Adding ceramic polishing waste as filler to reduce paste volume and improve carbonation and water resistances of mortar. Adv. Bridge Eng. 2021, 2, 3. [CrossRef]

21. Senthamarai, R.M.; Manoharan, P.D. Concrete with ceramic waste aggregate. Cem. Concr. Compos. 2005, 27, 910-913. [CrossRef]

22. Duan, Z.; Poon, C.S.; Xiao, J. Using artificial neural networks to assess the applicability of recycled aggregate classification by different specifications. Mater. Struct. 2017, 50, 1-14. [CrossRef]

23. Xianggang, Z.; Shuren, W.; Xiang, G. Mechanical Properties of Recycled Aggregate Concrete Subjected to Compression Test. J. Eng. Sci. Technol. Rev. 2018, 11, 20-25. [CrossRef]

24. Correia, J.R.; de Brito, J.; Pereira, A.S. Effects on concrete durability of using recycled ceramic aggregates. Mater. Struct. 2006, 39, 169-177. [CrossRef]

25. Daniel, R.J.; Sangeetha, S.P. Experimental study on concrete using waste ceramic as partial replacement of aggregate. Mater. Today Proc. 2021, 45, 6603-6608. [CrossRef]

26. Beregovoi, A.; Derina, M. Assessment of the Effect of Energy Saving and Heat Loss through External Enclosure Structures with Low Resistance to Air Penetration. In IOP Conference Series: Materials Science and Engineering; IOP Publishing: Bristol, UK, 2020; Volume 960.

27. Yu, L.; Wang, H.; Wang, X.; Feng, G. Study on the measurement of indoor environment quality and enclosure structure thermal defects of green residential buildings in severe cold areas. Procedia Eng. 2017, 205, 3373-3380. [CrossRef]

28. Wang, Y.; Li, B.; Chen, C.; Jia, H. Influence of groundwater level fluctuation on lateral deformation of cantilever enclosure structure of pit-in-pit. Mar. Georesour. Geotechnol. 2020, 38, 108-113. [CrossRef]

29. Zhang, Y.; Wang, Y.; Zhou, J. Research on two-dimensional heat transfer characteristic of enclosure structure. In IOP Conference Series: Earth and Environmental Science; IOP Publishing: Bristol, UK, 2019; Volume 252.

30. Liao, Y.; Zhan, J.H.; Li, C. Research on the Construction Monitoring for Enclosure Structure of Working well. Appl. Mech. Mater. 2014, 580, 797-800. [CrossRef]

31. Katunský, D.; Bagoňa, M.; Baláž, R.; Lopušniak, M.; Zozulák, M. Long-term monitoring of the thermal insulation properties of building envelope structures in real climatic conditions. In IOP Conference Series: Materials Science and Engineering; IOP Publishing: Bristol, UK, 2018; Volume 415.

32. Yang, Q.; Kong, L.; Tong, H.; Wang, X. Evaluation Model of Environmental Impacts of Insulation Building Envelopes. Sustainability 2020, 12, 2258. [CrossRef]

33. Ma, G.; Zhang, Y.; Li, Z. Influencing factors on the interface microhardness of lightweight aggregate concrete consisting of glazed hollow bead. Adv. Mater. Sci. Eng. 2015, 2015, 1-15. [CrossRef]

34. Wu, H.C.; Sun, P. New building materials from fly ash-based lightweight inorganic polymer. Constr. Build. Mater. 2007, 21, 211-217. [CrossRef]

35. Chai, Y.L.; Song, Z.Q.; Li, Z.; Zhao, L. Experimental study on working performance of bearing and insulating concrete with glazed micro-beads. J. Constr. Technol. 2013, 42, 83-87.

36. Huang, X.; Yao, W.; Pang, J. Carbonation Resistance Performance and Micro-Structure Analysis of Glazed Hollow Bead Insulation Concrete. Infrastructures 2019, 4, 63. [CrossRef] 
37. Song, B.; Yao, L.; Li, B. Calculation and Analysis of Heat Transfer Performance of Vitrified Micro-Bead Recycled Concrete Composite Columns Based on ANSYS. In Proceedings of the International Conference on Biology, Chemistry and Medical Engineering, Hefei, China, 29 June 2019.

38. Sekar, T.; Ganesan, N.; Nampoothiri, N.V.N. Studies on strength characteristics on utilization of waste materials as coarse aggregate in concrete. Int. J. Eng. Sci. Technol. 2011, 3, 5436-5440.

39. GB/T 50081-2002. Standard for Test Methods of Mechanical Properties of Ordinary Concrete, China; Ministry of Construction of the People's Republic of China: Beijing, China, 2007.

40. GB/T 10294-2008. Determination of Steady-State Thermal Resistance and Related Characteristics of Thermal Insulation Materials, China; Ministry of Construction of the People's Republic of China: Beijing, China, 2008.

41. GB/T 50080-2016. Standard for Performance Test Method of Ordinary Concrete Mixture, China; Ministry of Construction of the People's Republic of China: Beijing, China, 2016.

42. GB/T 50080-2002. Standard for Performance Test Method of Ordinary Concrete Mixture, China; Ministry of Construction of the People's Republic of China: Beijing, China, 2003.

43. GB/T 16594-2008. General Rules for Measurement of Length in Micron Scale by SEM; ISO: Geneva, Switzerland, 2008.

44. GB/T 30904-2014. Inorganic Chemicals for Industrial Use: Crystal Form Analysis on X-ray Diffraction Method; ISO: Geneva, Switzerland, 2014.

45. ISO 19618-2017. Measurement Method for Normal Spectral Emissivity Using Blackbody Reference with an FTIR Spectrometer; ISO: Geneva, Switzerland, 2017.

46. Zhao, L.; Li, Z.; Wang, W.J. Effect of adding glazed hollow beads on mechanical properties and thermal conductivity of concrete. J. Constr. Technol. 2015, 44, 63-66.

47. Liu, Z.W.; Zhao, K.; Tang, Y.F.; Hu, C.; Hu, M. Influence of lightweight aggregate on the properties of foamed concrete. J. New Build. Mater. 2019, 46, 19-23.

48. Amin, M.; Tayeh, B.A.; Agwa, I.S. Effect of using mineral admixtures and ceramic wastes as coarse aggregates on properties of ultrahigh-performance concrete. J. Clean. Prod. 2020, 273, 123073. [CrossRef]

49. González, J.S.; Gayarre, F.L.; Pérez, C.L.C.; Ros, P.S.; López, M.A.S. Influence of recycled brick aggregates on properties of structural concrete for manufacturing precast prestressed beams. Constr. Build. Mater. 2017, 149, 507-514. [CrossRef] 